\title{
The Ordering of Medical Things Medical practices and complexity
}

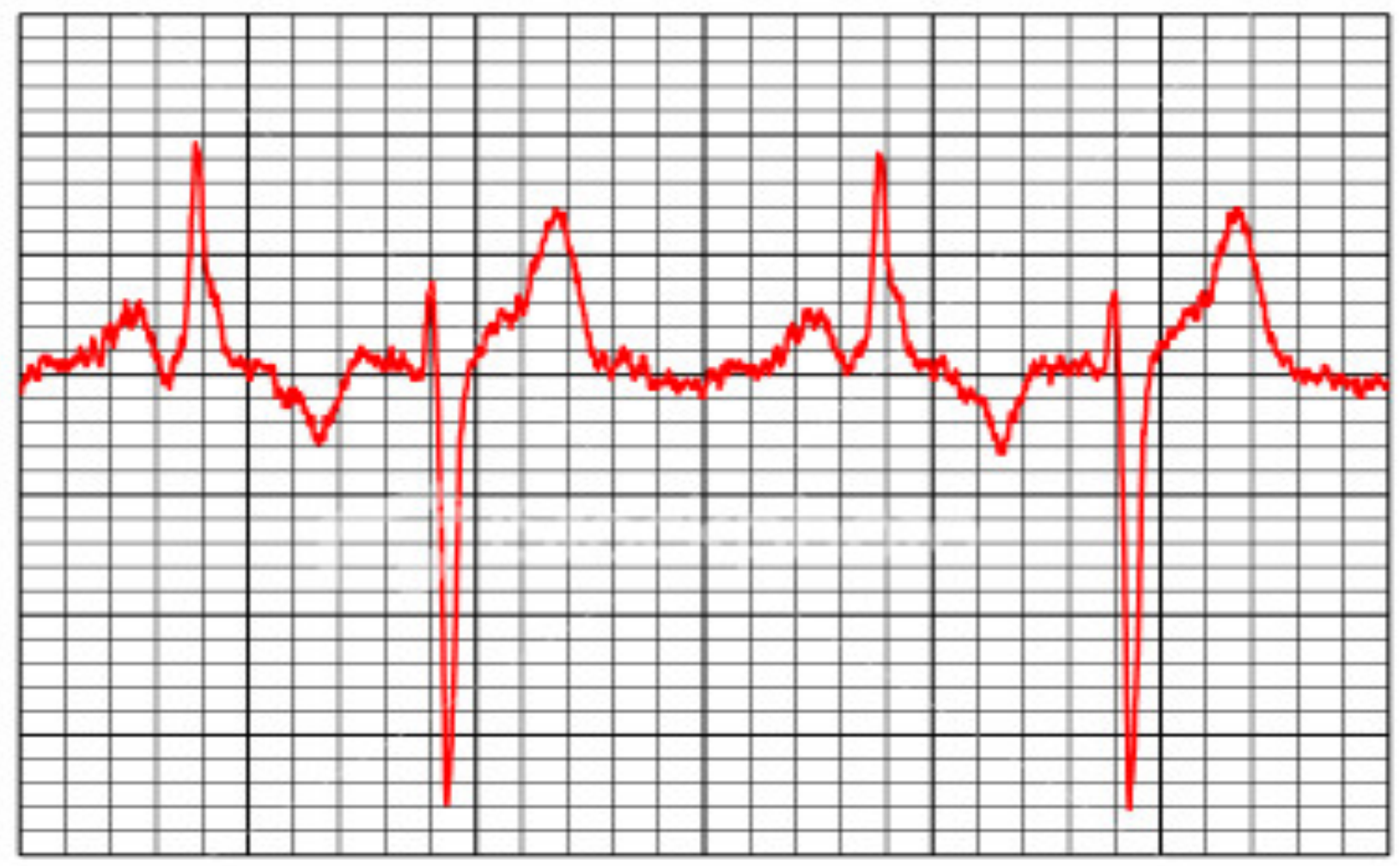

John Gardner

Masters Thesis, Victoria University of Wellington 


\section{The Ordering of Medical Things Medical Practices and Complexity}

John Gardner in fulfilment of the requirements for the degree of Master of Arts in Sociology 
Abstract $\quad 2$

Acknowledgements 3

Introduction 4

Part 1 - The Metaphysics of ANT 11

Complexity and sociology 12

Notes on power 32

A restatement of points $\quad 42$

Part 2 - Medicine in Action 46

Section 1: Enacting pain $\quad 48$

A sociology of pain $\quad 48$

The consultation

1 - Interactional construction 51

2 - Fluid translations $\quad 55$

3 - Probability as intelligibility 57

4 - The product of differing concerns 58

5 - Consolidation 60

6 - Multiple preoccupations 62

Section 2: Enacting the Heart 64

A sociology of techno-bodies 66

The treadmill test

1 - Aligning the elements 71

2 - Transformation of matter $\quad 76$

3 - Speaking for the heart $\quad 77$

Section 3: Coordinating reality 81

A sociology of reality $\quad 82$

The post-treadmill debrief

1 - Symptom-cause coherence 84

2 - Destabilising enactments 87

3 - Surveillance and self management $\quad 88$

Discussion - The ordering of things 95

$\begin{array}{ll}\text { Bibliography } & 108\end{array}$ 
This project is an investigation into medicine in action. The aim is to understand how medical interactions generate order via the diagnosis of disease; how the patient, the body, and illness are made intelligible, and how particular courses of action are decided upon as a result. Using video and audio data supplied by the Applied Research on Communication in Health (ARCH) research team, this project follows Simon, a middle aged, Caucasian male with chest pain, as he participates in consultations with his GP and cardiologist, and as he undergoes a cardio treadmill-stress test.

This project argues for adopting an Actor-Network theory (ANT) based approach to studying interactions. Unlike more traditional sociology approaches, this project considers the role of non-human objects in interaction. Non-human objects are often key actors in the interactions that provide the world with a sense of order. I will provide an epistemological justification for ANT's key premises and outline the method that these premises entail.

Following three interactions, this project illustrates that the principal actors involved in producing intelligibility varies. In the GP consultation, the GP and Simon were principal actors in rendering chest pain intelligible. In the treadmill stress test, the material instrumentation, carefully aligned with the Simon's body by the cardiologist, was vital to ensuring a particular account of the heart was produced. Simon was little more than a compliant body in this interaction. In the final interaction, the cardiologist was the principal actor in making sense of these accounts of chest pain and the potentially conflicting picture of the "healthy" heart. The cardiologist suggests that the account of the heart produced by the treadmill-stress test may be flawed, and encourages Simon to self-monitor and self-regulate. I will argue that the uncertainty generated by conflicting accounts is common to medical practices. Medical professionals respond to this by encouraging individuals to monitor and reduce risk. By adopting the ANT approach, I found that the patient and his body are sometimes intelligible as somatic entities, sometimes as an expressive, accounting agent, and sometimes as a self-responsible individual. These various renditions hold together as a being a single individual "Simon". 


\section{Acknowledgements}

This thesis would not have been possible without the Applied Research on Communication in Health (ARCH) research team, based at the University of Otago. The data for this thesis was collected as part of a Marsden funded project (2006-2009): Tracking healthcare interactions: patient-professional communication. Professor Kevin Dew and Maria Stubbe were the principal investigators for the project, Professor Tony Dowell, Lindsay MacDonald and Libby Plumridge were the associate investigators, and Rachel Tester is the data manager for the ARCH Corpus. The ARCH Corpus is a searchable, digitised collection of video recorded health care interactions and related data for use in interaction analysis. The collection currently comprises over 300 recordings and is based in the Department of Primary Health Care and General Practice, University of Otago, Wellington. My task therefore, was to simply choose an interesting data set from this corpus and get on with forming and articulating my argument. I would especially like to thank Rachel for her patience while assisting me with accessing the data. This thesis, then, represents not just my own work, but the hundreds of hours of work undertaken by the ARCH team. I am extremely grateful.

Throughout this project, I have had constant advice, support and encouragement from my co-supervisors, Professor Kevin Dew and Dr Mike Lloyd of Victoria University of Wellington. I thank them both very much for all the time and assistance they have given me.

I would like to thank Torrance for his rigorous, sometimes scathing, but always invigorating opinions on my writing and ideas. Many of the theoretical points here have been developed in our various, caffeine-hyped exchanges.

Lastly, I would like to thank Matthew, my companion for the last two years. Matthew - with your work and your inexhaustible enthusiasm, you have been a superb role-model. But most importantly, you have provided me with constant emotional support, without which I would not have been able to complete this project. I cannot express how grateful I am. 


\title{
Introduction
}

\begin{abstract}
Structural phenomena... are the emergent products of a vast amount of communicative, perceptual, judgmental, and other 'accommodative' work whereby persons, in concert and encountering 'from within society' the environments that the society confronts them with, establish, maintain, restore and alter the social structures that are the assembled products of the temporally extended courses of action directed to these environments as persons know them. (Garfinkel 1963: 187-8)
\end{abstract}

Harold Garfinkel and his disciples viewed social order as being the accomplishment of everyday interactions between individuals. Rather than assuming that consensus and cohesion are imposed upon members by a collective body, social order, and indeed disorder, is seen as the product of the practical reasoning and practical actions of negotiating individuals. Through talk and action, individuals simultaneously make senseof, and compose, group activities. Society, then, is a product; it is the ongoing effect of the diverse interactions between individual agents. Accordingly, ethnomethodologists and ethnographers argue that if we wish to understand how society is ordered as it is, then we must observe these everyday, often mundane interactions. We must follow individuals as they make sense-of, and engage in, social activities. My project follows this key tenet. The intention of this thesis is to understand how the interactions that constitute medical practices generate order through the diagnosis of disease. By observing patients and medical professionals as they produce accounts of reality and negotiate these accounts, we will see how facts are discerned from non-facts, and thus how intelligibility is achieved. 
The medical interactions that we will be following are centered on one particular patient, referred to here as Simon. Simon is a middle-aged, Caucasian male who has been experiencing chest pain. He has an initial consultation with his GP and is referred to a cardiologist, who conducts a test aimed at determining the health of his heart, and then provides Simon with a diagnosis and some advice on maintaining a healthy lifestyle. These interactions have been captured on video and audio data by the Applied Research on Communication in Health research team (ARCH) based at the Wellington campus of the Otago School of Medicine. Using this data I will note how it is that, through these medical interactions, Simon and the other individuals involved are able to make sense-of their world and thus engage in particular courses of action. In other words, we will see exactly how it is that order is an achievement of such interactional practical reasoning and practical action.

The advantage of ethnomethodology and ethnography based approaches is that they allows us to see the messiness of practices. As one commentator points out, rather than relying on official, clean, and prepared reports of the processes of fact-finding, discovery and diagnosis, these approaches allow the social researcher to witness the often untidy, contingent and diverse means by which knowledge is created (Law 2004: 18-19). Importantly, these methods therefore have the potential to reveal those many instances where a clear, definitive understanding of the world is not achieved; where interactions generate, and are centered upon, uncertainty and ambiguity. For this project, then, such an approach allows us to trace not only those circumstances in medical practice where a definite diagnosis is achieved, but also how indefinite, tentative diagnoses come about, and how these uncertainties are dealt with by the individuals themselves.

Where this project differs from traditional ethnomethodology and ethnography, however, is that I will not simply be focusing on the interactions between human actors. What I hope to demonstrate in the course of this thesis is that in the contemporary world, particularly in medical contexts, a great deal of the work done in accomplishing order and intelligibility is done by non-human objects. Here I will be employing ActorNetwork Theory (ANT), particularly the work of Bruno Latour and Annemarie Mol. While more traditional approaches stress that reality is culturally and historically located, ANT emphases that it is also materially located (Mol 1999: 75). Interactions between individuals often involve non-human objects whose material form can shape the 
production of accounts and the understandings that result. Such objects are therefore vital in how people make sense-of their situation and the sort of activities they subsequently engage in. By using an ANT-based method, I will draw attention to the various ways that material objects shape the production of accounts and intelligibility in medical practices. This project, then, is not just an ethnography of interactions between humans and humans, but also humans and objects.

This project is divided into two main parts. Part 1, The Metaphysics of $A N T$, is an epistemological justification for the ANT-based approach I am using. I will explain the theoretical basis for the central tenets of ANT, and illustrate how these tenets influence the methodology of the sociology that follows. Firstly, I will show that ANT is based on a conception of "social" that differs markedly from that which informs traditional sociological approaches. In the sense that we will be using the term, "social" is what happens when things associate, whether they be humans or non-humans, material or discursive. With this conception of the "social", we cannot exclude material, non-human objects from sociological accounts. Secondly I will illustrate how ANT provides us with a different conception of scale. By casting aside the traditional macro/micro division and focusing on the associations that form between both human and non-human entities, we will see that scale is a matter of connectedness: the more associated an entity is and the more connections it has with other elements, the more influential it is and the larger it seems. Here I will employ DeLanda's notion of emergence to demonstrate that with this notion of scale we can still conceive of "larger" order phenomena that cannot be reduced to their constituent parts. Consequently, social order and the production of accounts cannot necessarily be explained in terms of the actions of individuals. Using DeLanda's notion of capacities for interaction, I will also show that it is through associations that entities become intelligible: as an entity interacts with another, some of its qualities become perceptible. It is therefore though such interactions, or assemblages, that individuals can make sense of their world. Thirdly, I will illustrate that with this method we are led to a radical conception of the "actor". Rather than an actor being the source of an action, it is a point where action is converted, or translated, into another type of action. Actors are made to act, to associate with entities, via other actors. They are not an a priori source of action, but instead the temporary product of an assemblage between actors. According to this definition, non-human entities have the ability to become actors. 
I will then go on to illustrate how this metaphysics leads us to a sociological method of "following the actors". If we wish to understand how it is that interactions generate understandings of the world, how it is that intelligibility is produced, then we must follow human and non-human objects as they associate to form assemblages. We must identify which entities, human or non-human, are inducing assemblages and are therefore actors, and must note how, through the resulting interactions, entities are endowed with form and thus become intelligible. Noting how some humans and nonhumans are prevented from becoming part of an assemblage will allow us to see how other potential forms of intelligibility are elided. If we are to follow a patient in a medical context then, we must note which entities they become associated with, such as medical professionals, medical instruments and equipment, and documentation; who or what are the actors that initiate these associations; what form a patient, their ${ }^{1}$ illness, their body and other entities are subsequently endowed with; and how such associations may restrict other possible understandings from being achieved.

Part 1 ends with a discussion of power. ANT, I will argue, is well suited to exposing the relations that constitute power. Here I will discuss Foucault's rendering of the concept as both a productive and repressive force and I will add that, contrary to some criticisms, Foucault did account for states of domination. By following the actors in medical practices and tracing the formation of associations, we can see how it is that relations can be productive, in that they produce particular kinds of patients and bodies; and repressive, in that they can prevent the expression of alternative forms of the patient and body. I will argue that associations which have become durable or more stable can result in perpetually asymmetrical power relations, or domination. Such associations can be found in various medical technologies, which, due to the fixed nature of their componentry, dictate what sort of entities will be included in assemblages that produce accounts of the body. In this particular case, these entities are nearly always somatic, and are employed at the exclusion of the patient's expressions, anxieties and opinions. In medical contexts, then, it is not unusual for technologies, when used by highly trained staff, to produce accounts of the body that have no input from patients themselves, aside from a sample of ir body. ANT, I will argue, provides an excellent method for

\footnotetext{
1 "Their" and "they" will be used as singular indefinite pronouns throughout this project, in order to avoid using the awkward "his or her" and "he or she". This is acceptable usage according to the 2004 edition of The Cambridge Guide to English Usage.
} 
uncovering how it is that medical practices, particular those that involve non-human objects, generate order during the processes of diagnosis. Not only does it allow us to identify how entities become intelligible, but also how, through technologies, the same type of somatic-based accounts are produced again and again.

The second part of this thesis, Medicine in Action, is the application of this ANT-based method to the case study. Using the collected video and audio data, we will follow the patient, Simon, as he becomes entwined in three separate medical practices, all of which aim to discern the nature of his chest pain. Part 2, then, is divided into three sections, each section focusing on one of the medical practices. The first section, Enacting Pain is based on Simon's consultation with his GP. Here Simon explains to his GP that he has been experiencing some chest pains, and via the GP's line of questioning, he explains whereabouts on his body it is located, how often it occurs, and he also discloses a history of smoking and a family history of heart disease. Additionally, Simon indicates that his pain may be related to anxiety. Here I will show how, through the interaction between Simon and the GP, chest pain becomes intelligible and subsequently becomes the basis for initiating further courses of action.

One course of action that the GP recommends is that Simon undergoes a treadmill stress test. This is the focus of Section Two, Enacting the Heart. The treadmill stress test takes place at a specialist clinic, and is conducted by a cardiologist with the aid of a technician. The test requires Simon to run on a treadmill, thus stressing the heart, while he is attached to a device producing an electrocardiogram or ECG. Simon is told by the cardiologist that this device will indicate whether his heart is damaged and is the cause of his chest pain. Conducting the test involves the very careful and controlled construction of an assemblage which insures that only a select few entities within Simon's body are made to interact and thus produce an account of the heart. The cardiologist and the technician are the principal actors in producing this account, while Simon is rendered little more than a compliant body. At the conclusion of the procedure, the cardiologist states the test indicates that Simon's heart is healthy and free from blockages or narrowings that might cause chest pain.

The third section, Coordinating Reality, is based in the post-treadmill test debrief between the cardiologist and Simon. Here the cardiologist attempts to make sense of the account of chest pain that was produced in the GP consultation, and the account of the heart that was produced by the electrocardiogram. There is a potential conundrum here 
for the cardiologist. He must somehow make sense of the fact that Simon is experiencing chest pain, yet his heart appears to be healthy. He therefore employs two tactics to ameliorate the possible contradiction. Firstly, he postulates another cause: the pain, he states, is probably related to anxiety, or may even be stomach-related. Secondly, he questions the reliability of the account produced by the treadmill stress test: he states that it is a simple, fallible screening test, and may not provide an accurate picture of the heart. Simon is therefore told that his heart is probably healthy, but because this cannot be guaranteed, he should self-monitor his body for additional symptoms, and also selfregulate his everyday activities to insure he engages in plenty of exercise while avoiding certain foods and cigarettes. Here, then, we have an interaction, an assemblage, that produces an indefinite diagnosis of the heart: the heart is most likely healthy, but because this is not assured, Simon must carefully regulate his behavior. Additionally, then, we also have the production of a certain type of patient: a self-monitoring, self responsible individual.

The project concludes by suggesting that perhaps a lot of medicine is conducted in this fashion. Rather than making a definite, assured diagnosis, medical professionals are often dealing more with probable diagnoses and managing the risks that this uncertainty entails. I will also discuss what we have witnessed in relation to the biomedical model which is said to underlie medical practice. Some tenets of the biomedical model do appear in some of the practices we will follow, such as the ignoring of non-somatic elements in the production of accounts of the body during the treadmill stress test. This was not so in the GP consultation, where the patient's family history, lifestyle and anxieties were utilized in the production of the account. It is unfair to chastise medicine as a whole, therefore, for adhering to the biomedical model. I will also argue that during Simon's foray in the healthcare system, he was essentially enacted as three types of patient. In the GP consultation, he was an accounting, expressive actor. In the treadmills stress test, he was simply a compliant, fleshy body, and in the post-test debrief, he was encouraged to become a self-responsible individual. Using Mol's term, he represents a patchwork singularity (2002): he is the product of three assemblages or interactions, bound together as one, single patient: "Simon". I will end by stating that with the method we have adopted, the sociologist is well placed to challenge those circumstances in medicine where domination is occurring. If indeed medicine does often deal with indefinite diagnoses and uncertainties, then we should be suspicious of those 
cases where certainty is being claimed, particularly if the account that is produced is causing considerable stress for the patients. Here I use Rhodes et. al. (2002) example of patients with chronic back pain, who have been told by medical professionals that, according to the accounts produced by various instruments, there is nothing physically wrong with them. In such circumstances, the sociologist can challenge such accounts by emphasizing the inherent uncertainty of accounts, as we witnessed in our case study. By highlighting uncertainly, we can potentially provide a margin for the patient to be more included in the production of accounts of their own body.

This project, then, is something of a proposal about how sociology of medicine can be conducted. Following in the vein of Garfinkel's studies of everyday interactions, and by expanding our vision to include non-human entities, we can unravel how it is that order is achieved: how it is that humans and non-humans construct an intelligible world and thus a world were actions take place. The goal, to play on a phrase of Foucault's, is to witness the everyday ordering of things: the ordering of objects and instruments, individuals and bodies, patients and medical professionals. In addition, the sociologist can do more than simply provide their own descriptive accounts. With a detailed knowledge of such ordering practices, the sociologist, it is hoped, can intervene, should there be a political or ethical imperative to do so. 


\section{1 - The Metaphysics of ANT}

The most RECEnT EDITION of the Oxford Dictionary of Sociology makes no mention of the approach that forms the basis of this thesis. Actor-Network Theory (ANT) has emerged from Science and Technology Studies and its proponents have, for some time now, been making a case for its inclusion into sociology practice. If the content of the Oxford Dictionary is taken as a statement of what sociology is, then these proponents still have some work to do. It is perhaps not surprising that there has been some reluctance to include ANT into the sphere of accepted sociology. Some of its key premises initially seem quite odd and are incompatible with the more popular and traditional approaches in sociology: the social is flat, non-human objects can be actors, spatial and temporal scales are the effect of actors, to name a few oddities of ANT. These peculiar assertions are the result of a metaphysics that has no heritage in the work of Marx, Durkheim or Weber; the founding fathers of sociology, or even in the enlightenment forefathers, Kant and Hobbs. 
Instead, ANT has its lineage in the work of other thinkers. ANT was generated in response to following scientists in the laboratory (see Latour and Woolgar 1979/1986) but many of its key principles are found in the work of Gabriel Tarde and Manuel DeLanda. The approach I am adopting here diverges markedly from what sociology is usually considered to be. Except for the purposes of comparison, there is no mention of Durkheim or Weber, and certainly no lengthy exegesis on the work of Marx. My intention in this first section is to outline the metaphysics I will adopt in this thesis; a metaphysics that is indebted heavily to Tarde and DeLanda and forms the basis of the ANT approach that I am using. I hope to show how it is that ANT espouses such seemingly odd premises and, more importantly, how such principles provide us with a very useful and insightful method for the sociology of medicine.

\section{Complexity and Sociology}

The motivation here for jettisoning a traditional sociological approach is that ANT is far better suited to dealing with complexity. Traditional approaches, particularly those associated with adherents to Weber, Durkheim and Marx, cannot fully explicate social phenomena because they deal with complexity by prematurely attributing causation to preset agents or structures (Latour 2005: 47-49). In the metaphysics I am adopting here, there are no preset agents or structures and therefore no hasty assigning of causation. Complexity is seen not as something that must be overcome but rather as something that is necessary for a good sociological account. Before I explain this point, let's begin with an example of complexity. Below are four pictures of cardiovascular disease, each are real-life accounts and each can be said to be true in that they represent a largely uncontested reality of the disease.

\section{Picture 1}

Cardiovascular disease was the second leading course of death after cancer in New Zealand in 2003, with 6196 deaths. The mortality rate has shown a downward trend, of about 50 percent, from 1987 to 2003. During this period males have had a consistently higher age-standardised mortality rate than females. In 2003, the male rate was 94.1 percent higher than the female rate, although the male mortality rate does appear to be falling faster than that of females. Males succumb to the condition at a slightly earlier age than females; however, the mortality frequency is skewed toward the 65 plus age group for both sexes. In 2003 the calculated Maori male age-standardised rate was 120 percent higher than that of non-Maori male rate, and the calculated Maori female rate was 84 
percent higher than the non-Maori female rate. The Ministry has sourced data from certificates of cause of death from doctors and coroners, post-mortem reports from private pathologists and hospitals and death registration forms. In order to reduce the overall heart disease morbidity and mortality rates, the Ministry has set a Health Target of improving nutrition, increasing physical activity and reducing obesity. The Healthy Eating - Healthy Action (HEHA) Strategy is the Government's multi-faceted, integrated initiative to achieving this target. HEHA aims to encourage an "environment and society where individuals, families and whanau, and communities are supported to eat well, live physically active lives, and attain and maintain a healthy body weight". (Ministry of Health, Manatû Hauora 2006, 2009)

\section{Picture 2}

Ischemic heart disease is characterised by coronary atherosclerosis. Atherosclerosis results from the damaging of the endothelium that forms the internal wall of an artery. This is made up of smooth muscles cells, which, when damaged, fail to produce Nitrous Oxide (NO), a suppressor of immune function. In the absence of NO, the damaged endothelium produces a series of immune cell attractors, resulting in the recruitment and binding of macrophages and other immune cells to the damaged area. These immune cells infiltrate the damaged area and promote the production of more, non-NO producing smooth muscle cells. Over time, fats, cholesterol and calcium adhere to the inflamed area. These deposits gradually build up and form a light-yellow plaque that narrows the lumen within coronary arteries, severally restricting blood flow. This plaque becomes calcified, and in some cases may rupture resulting in a thrombus. The result of coronary atherosclerosis is recurrent angina and in many cases myocardial infarction. (Cheong 2004)

\section{Picture 3}

AstraZeneca today announced that it has entered into a licensing deal with Atherogenics, Inc. for the development and commercialisation of their anti-inflammatory cardiovascular product candidate, AGI-1067. AGI-1067 is an oral drug for the treatment of the underlying cause of cardiovascular disease, atherosclerosis. Under the terms of the agreement AtheroGenics will receive and upfront fee of $\$ 50$ million and if successfully commercialised, AtheroGenics will be eligible for fees and milestones of up to $\$ 1$ billion. "The collaboration with AtheroGenics is an important step in AstraZeneca's plans to further strengthen its cardiovascular franchise", said Dr John Patterson, Executive Director, Development for AstraZeneca. The partnering of these two companies represents a win-win situation: AstraZeneca gets exclusive access to the drug while AtheroGenics will benefit significantly from the commercial success. "AGI-1067 has the real potential to further enhance our position among the leaders in cardiovascular medicine." The commercialisation of AGI-1067 would also provide AtheroGenics with additional resources to begin its transition from a research and development organisation to a commercial enterprise. (AstraZeneca 2005) 


\section{Picture 4}

David Slack recently threw a party. As guests arrived, the amiable host affixed plastic hospital ID bracelets to their wrists. Canapes and hors d'oeuvres were served by Mary Margeret, Slack's daughter who wore green surgical scrubs and delivered her snacks on a hospital trolley. The medical paraphernalia was far from gimmicky. For Slack, 48, was celebrating his " $21^{\mathrm{st}}$ " -21 years since he suffered a heart attack that doctors described as "catastrophic". Slack went on to tell of the day when he received a grim prognosis at Dargaville Hospital. "If there's any light to go towards, I didn't see it. I've been smacked in the face and its hurt more than the pain in the chest, but the whole nausea and sense of dislocation and general unease and imminent collapse is very perturbing. Even my natural optimism couldn't overcome that, and it took me quite a while to get over the notion that my life really might be truncated." After more than two decades of physical self improvement, the North Shore local's future looks bright. Having retooled his diet and cut out his vices, he plans to run a marathon. This year, after listening enviously to his brother's tales of participating in races in New York and Helsinki, he is keen to complete the full $42 \mathrm{~km}$. "This is the kind of thing that really does help you persevere. You do the training for a marathon and everything else about your health drops into step as well," he says. "And it feels great". (Nippert 2008)

These four pictures all represent some reality of cardiovascular disease, each incorporating different elements into their account. As we can see, cardiovascular disease is not just a medical phenomenon. It is entwined in commercial practices, discourses on governance and individual life-histories and it can be made intelligible in terms of ethnicity, gender and population eating habits, cellular and molecular aetiology, commercial strategy and chest pains, nausea and unease. Although the four pictures are quite different, none need be considered any less real than another. This heterogeneity of disease raises a question for the social scientist who wishes to undertake a study into medicine: how do we go about deciding what sort of elements should be included in a sociological account of the disease? If we were to include all elements, then a sociological account would potentially be unmanageable.

At this point I will borrow a concept from the philosophy of science: supervenience. The term is used to describe the relationship between sets of properties, where one set (set A) of properties is established by another set (set B). This relationship is not reciprocal, however. Set B may come about through the existence of other sets, or a collection of sets, without the presence of Set A (Sober 200: 74-75). This analytical term is useful for us here because it adequately describes the relationship of cardiovascular disease to the sets of elements presented in the above accounts. In each of the accounts, cardiovascular disease is brought about through the existence of a distinct set of elements and no one set or type of properties seems to be essential for 
cardiovascular disease to be intelligible: there is no mention of nitrous oxide and endothelial damage in the life-history, and there is no mention of ethnicity, gender and Healthy Eating, Healthy Action in the commercial account. In this respect, cardiovascular disease supervenes on a range of elements or properties, some of which are "commercial", some of which are "biomedical" and some of which are "personal". Endothelial damage, nitrous oxide production and macrophage recruitment are elements of the diseases, just as are poor diet, obesity and ethnicity.

It is important to note here that cardiovascular disease supervenes on elements that vary in size and complexity. From population eating habits and commercial initiatives to macrophages and molecules of nitrous oxide, there is no straightforward relationship between macro and micro, complex and simple. As any epidemiologist would inform us, understanding the occurrence of disease requires a knowledge of various large scale population factors, not just cellular aetiology. Following threads, we may begin with a damaged endothelium and find ourselves moving through the world of corporate strategy, multi-million dollar transfers and shareholders; or, alternatively, we may just as easily find ourselves amongst the everyday anxieties of families: pain, loneliness and death. The unsettling realisation that supposedly "micro" elements are composed of "macro" elements with just as much frequency as the reverse indicates that these a priori definitions of scale are perhaps not very useful at all.

Adding to this dizzying perplexity of scale is a problem of quantity. Already in the pictures above we are presented with numerous elements, but these elements also supervene on others, which, in turn, supervene on other elements and so on: Nitrous oxide behaviour supervenes on particular atomic capacities; obesity supervenes on exercise patterns, calories and modern work habits; AGI-1067 supervenes on business models and a plethora of legal considerations. Here is the conundrum for a sociologist, or indeed any specialist, who wishes to make sense of the disease: if cardiovascular disease potentially supervenes on an endless quantity of elements, how do we decide which require further explication and which ones to ignore?

These problems of scale and quantity reflect the monadic character of the disease. The "monad" provides a useful analytic tool for understanding the sort of complexity and mess that I have highlighted above, and it will also provide me with a starting ontological framework for this thesis. This term originated in Leibniz's work (1714) and was adopted and modified by the French sociologist Gabriel Tarde 
(1893/1999), a contemporary of Durkheim. Tarde and Durkheim had very different conceptions of society which led them to two very different assertions for how sociology should be conducted. Durkheim promoted a sociology that studied social facts. These, he argued, have an independent existence outside of the actions of individuals and are distinct from material or physical phenomena. Social facts constitute a "social reality" which exists prior to the realities of individuals, informing their behaviour and thus providing society with rigidity (Durkheim 1982). By examining social facts, he argued, the sociologist can come to understand the behaviour of entire societies. Here, society is seen as the cause of associations between people ${ }^{2}$. Tarde, however, made no such distinction between the social and the individual, or the social and the physical or material: "everything is a society and that all things are society" (Tarde, cited in Latour 2005: 218). "Social" is what happens when things associate, and these things may associate in a physical way, a biological way, a legal way or a religious way. Society is the consequence of associations, not their cause (Latour 2005: 238). For Tarde, the "social" is often material, and tracing which things associate together and how this is achieved is the key to understanding the composition of the resulting society (Latour 2005: 13).

Leibniz's notion of the monad provided Tarde with a useful analytical tool for conceptualising this idea of societies. According to Tarde, the universe is made of monads which are not material entities in-themselves, but neither are they ideal forms or representations of things. A monad is a group of associated elements, aggregates, which have a material existence. Monads do not have any goal or grand design, they do not exist because of their function and while their form may change this cannot be explained in terms of some "higher order" (Latour 2001: 2). Importantly, the associations that compose a monad are heterogeneous in that the elements involved may be either human or non-human; neither type can be separated from the other or granted a status as being more "essential". Consequently, unlike the Durkheimiam tradition, there is no divide between society and nature, and envisaging such a divide does not aid in understanding

\footnotetext{
2 I have presented here what Levine refers to as Talcott Parson's "strikingly partial" reading of Durkheim, which focuses solely on the rationalist dimension of his work (1995: 46). Shilling and Mellor (1998) have argued that this widespread interpretation has overshadowed Durkheim's more nuanced exploration of embodiment, effervesces and the construction of social order found in The Elementary Forms of Religious Life (1915). Latour refers to The Elementary Forms as Durkheim's "Tardian moment" (2005: 38)
} 
human interactions. Cardiovascular disease, as we have seen, supervenes on a range of elements associating in ways that traverse any clear society/nature divide. A monad is composed of associations that are not ideal or spiritual, but are real, such as the interaction between immune cell attractors and macrophages, AtheroGenics and AGI1067, age-standardized mortality rate and sex. Following Tarde, all these associations are social and it is these numerous associations that comprise the social world.

Initially it may seem that this monadic conception of disease does not provide much aid to the sociologist, as the Tardian sociologist is confronted with a dizzying array of elements and complexity. Traditional sociology, following Durkheim, has a method for dealing with this complexity. By envisaging a social reality that is distinct from other realms, the Durkhiemian sociologist disregards most of the elements involved and instead focuses on those that are deemed "social". The risk of this approach, however, is that the sociologist has prematurely delimited the phenomena they are attempting to explain and their account loses explanatory power. If we follow the monadic conception, societies are the consequence of assemblages between heterogeneous elements and there is, therefore, no distinction between the "social" and other forms of association. A Durkheimiam risks overlooking the stuff that society is actually made up of. This leads me to the first premise of this project: If we accept that sociology can exist without having to envisage a separate social realm, and instead accept the complexity and beterogeneity of elements that constitute the social, we have the potential to trace phenomena as they are and therefore provide a more thorough account of the relations that constitute power. With the monadic conception, we are not provided with any a priori criteria for determining what type of elements should be included in a sociologist's account.

The monadic account of society also provides a very useful alternative way of thinking about scale. As we have seen in our pictures of cardiovascular disease, the disease monad supervenes on elements that vary markedly in scale: a component of cardiovascular disease is not necessarily smaller or less complex than the disease itself. In Durkheimiam sociology, scale and complexity increases as we move from the individual to the "higher order" society. In organic solidarity summarized in The Division of Labour in Society, the modern individual is socialised into particular, specialised roles and interrelations sanctioned by society, so that "although society is nothing without individuals, each one of them is more of a product of society than he is the author" (1984: 288). Solidarity is the result of complementary relations between actors who must cooperate 
with one another in order to meet those needs that their own, highly specialised labour cannot attain. Consequently, each individual is only ever the embodiment of a minute, discrete section of the collective whole that must encompass all the roles, beliefs and codes necessary for its own survival. Individuals are effectively rendered as an atom defined by their function in maintaining the higher order. Tarde's monadic account of societies leads him to make quite different assertions concerning scale. Firstly, the "smaller" entity is often more complex:

If we look at the social world... we see agents, the humans, much more differentiated, much more individually characterised, much richer in continuous variations, than the government apparatus, the system of laws and beliefs, even the dictionaries and the grammars which are maintained through their activities. An historical fact is simpler and clearer than any of the mental states of any of the actors participating in it. (Tarde, cited in Latour 2001: 4)

Secondly, Tarde illustrates that the so called "macro" is nothing more than the simplification and extension of one component of the "micro". He uses language as an example:

People who speak, all with different accents, intonations, pitches, voices, gestures: here is the social element, the true chaos of discordant heterogeneities. But in the long run, from this confusing Babel, a few general habits will be outlined and formulated in grammatical laws. (Tarde, quoted Latour 2001: 4)

Collectives, cultures, classes, and nation-states are the effect of the standardization and simplification of some qualities of their elementary components that, for whatever reason, have disseminated to some degree from their origin. The macro is nothing more than an extension of the micro (Latour 2001: 3). This is far removed from Durkheim's world. We no longer have a leviathan socialising individuals into functional roles: instead we have enormously diverse agents with complex habits, customs, opinions and beliefs, whose activities and inter-relations have no higher-order goal, but where some of these opinions, beliefs, habits and actions come to be rendered as representational or essential qualities. This extension or dissemination occurs when these qualities are actively practiced by agents outside of their origin, but it does not mean that they come to dominate the "society" they are said to represent. In Tardian sociology, the "macro" is not bigger, more complex or all-encompassing; it is simply those few qualities or goals of complex, elementary monads that have managed to become more connected by 
operating outside their original locus. With this in mind, a priori macro and micro divisions are of little use in attempting to uncover the associations that constitute society. Here we have the second premise of this thesis: The micro/macro distinction is not useful for understanding the relations that constitute power. What is useful is understanding how some qualities disseminate from their origin while others do not; how it is that some practices, beliefs or actions come to have an effect on elements that were not previously implicated, and how this effect is maintained.

The monadic conception has alleviated the problems of scale we encountered with cardiovascular disease. Rather than being faced with the confusing dilemma of a disease that supervenes on supposedly macro and micro elements, we have a monadic disease that supervenes on a range of elements whose complexity varies markedly according to the associations they form with other elements. Aside from this redefining scale and the prohibition on reifying a distinction between "social" and "material', there are other important consequences of using the monad as an ontological starting point. Firstly, it allows us to conceive of social parts without the risk of essentialism or functionalism. Since "macro" is simply the extension and standardisation of some qualities of elements, the complexity and diversity of elements always surpasses that of any supposed higher order. Individuals, groups or any assemblage cannot be adequately defined or understood simply in terms of their capacity to maintain any other assemblage or group. We can contrast this with Durkheim's conception of society, where individuals and groups are the result of the functional qualities invested within them by a society, and also classical Marxism, where social roles and occupations reflect the mode of production. While functionalism has largely been dismissed by academic sociology, this underlying logic concerning the relations between social parts is often still present in contemporary sociology, albeit in a more sophisticated form. As Manuel DeLanda puts it:

[the logic] still exerts considerable influence in most schools of sociology, and in this form it is more difficult to eliminate. This version involves not an analogy but a general theory about the relations between parts and wholes, wholes that constitute a seamless totality or that display an organic unity. The basic concept in this theory is what we may call relations of interiority: the component parts are constituted by the very relations they have to other parts in the whole. (DeLanda 2006: 9) 
The monadic account is comparable to Manuel DeLanda's assemblage theory of society and some more of his terminology is of use here. While functionalism and much contemporary social theory employs the relations of interiority model, monadology and DeLanda's assemblage theory assume relations of exteriority. Here, an element may be removed from one assemblage and placed in another, and although different capacities may be exercised as a result, its potential for entering particular types or relations remains unchanged (DeLanda 2006: 11). This indicates that its potential for interactions always exceeds what is actually realised by being immersed within a particular assemblage and it cannot, therefore, be reduced to any seemingly "functional" capacity that may be exercised. Elements, then, have innumerable capacities for interaction which are only perceptible when they become associated with other elements. We might define an element by some of its qualities for convenience, but its potential for expressing other numerous qualities means that it will always escape any attempt to determine the element's essence. All elements, then, have noticeable qualities or characteristics that are the result of being assembled with certain other elements, as well as numerous, indefinite, unactualised capacities which will potentially be realised when the element becomes part of a novel assemblage (DeLanda 2002: 71). We can see that this is very similar to the complexity that Tarde refers to. The complexity of elements always exceeds that of those qualities that have become so-called "macro", and by adopting Tarde and DeLanda's ontology (and at this point I am using "assemblage" and "monad" interchangeably), we avoid any tendency to essentialise elements or reduce them to any function they may serve. An important point here is that the intelligibility of an element is always the consequence of an assemblage: the elements within an assemblage are themselves assemblages, or to put this in Tarde's terms, we have monads within monads. Consequently, it is assemblages that construct our world and populate it with entities by making them intelligible through associations. It is only through associations that capacities are enacted, and atoms, molecules, cells, individuals, collectives, species, nation-states, and indeed the universe, become knowable.

While Tarde, as we have seen, illustrates how the supposed higher order is achieved through the extension and standardisation of some qualities of the elementary, there is an oversight that is remedied in DeLanda's assemblage theory. By abolishing the conception of the macro as being larger and more complex, we do not also need to forfeit the notion that the "macro" is no more than the aggregate of its parts. It is possible, according to DeLanda, for the "macro" to have properties that are different 
from the properties of any constituent elements. These emergent properties are the result of interactions between the exercised capacities of separate elements (DeLanda 2002: 72). So, some qualities of an element may be standardized and have an effect that extends outside of their original locus, and these qualities may also interact with those of other elements that have also been extended and standardized, resulting in a novel set of effects that are quite separate to those of the constituting elements.

The reason for the elaborate outline of this ontology is that it has major repercussions for the way sociologists approach their subject matter. If we were to follow the logic that underlies functionalism and much contemporary social theory, where social parts are constituted purely by the relations they have to other parts, then interactions between them would be logically necessary. That is, the parts are constituted by relations that are necessary for maintaining the whole, and therefore the investigation of parts can be done via thought alone. In the ontology I have adopted here, however, the interactions that occur between parts are not logically necessary, but continually obligatory (DeLanda 2006: 11). Emergent properties and the interactions between monads or assemblages are the consequence of complex inherent dynamics within elements that have no higher order objective. They are, essentially, unforeseen consequences. Since there is no general logic governing emergent properties, understanding how they come about, and how they are maintained requires an empirical method that can follow the complex, inherent dynamics that generate particular effects. The sociologist, then, must empirically investigate how it is that particular associations form between elements, and how some of these associations result in emergent properties.

If emergent properties cannot be reduced to elementary components, then we cannot equate causation with the activities of individuals. Contrary to the assertions of methodological individualists, it is possible for collectives or assemblages to act in ways that differ from the actions or intent of individuals that constitute them. As DeLanda puts it:

Assemblages larger than individual persons have an objective existence because they can causally affect the people that are their component parts, limiting them and enabling them, and because they can usually affect other assemblages... The fact that these assemblages must use people as a medium of interactions does not compromise their ontological autonomy anymore than the fact that some people must use some of their 
body parts to interact with the material world compromises their own relative autonomy from their anatomical components. (DeLanda 2006: 39)

Individuals may have needs, wants and impulses that they act upon, but their intended course of action will more often than not be hindered, distorted or transformed by other elements whose behaviour cannot be fully predicted or controlled. The actual outcome is different from what was intended, and explaining the result therefore requires an explication of all the elements involved, which are not, necessarily, other individuals. In this respect, verstehen is not a sufficient methodological approach for the social scientist. There is an additional reason why we should avoid conceiving the individual as a starting point for sociological enquiry. If elements have numerous capacities for interaction, and their intelligible form is the consequence of being assembled with other elements, then the individual is not a transcendendal universal but an effect; the consequence of various associations that enact particular capacities of interaction. This is a point that Latour makes quite clear: "to be a realistic whole is not an undisputed starting point but the achievement of a complex assemblage" (2005: 276). This is not to say that the individual as we know it is simply a product of "society", nor do we need to deny the materiality of the body; rather, in the ontology we have adopted here, we must recognise that the individual is the consequence of a complex assemblage like any other intelligible element. Figurations of individuality, subjectivity, personhood and decision-making are capacities that are being enacted by various interactions with other elements which may be acting across spatial and temporal distances. If a rational, individual human actor exists, it is a temporary product, not an a priori universal (Latour 2006: 207).

Michel Callon provides us with an illustration. Using Marie-France Garcia's work (Garcia 1986) on the establishment of a strawberry market in the region of Salogne, France, Callon demonstrates how the calculating, rational individual is the temporary product of various market practices. The strawberry market was modelled on neoclassical theory and its formation involved the careful arranging of devices to insure that agents and merchandise were clearly defined and dislocated from one another so that decentralised exchange could take place. Importantly, this involved the construction of a space of calculability: transactions were displayed on an electronic board, batches of produce (each with their own data-slip) were displayed side-by-side, the technique of digressive bidding, and formal measurement units were utilised. Buyers and sellers were 
also physically separated to insure that exchange was impersonal. This alignment of elements had the effect of configuring homo economicus: an informed, calculating agent (Callon 1999: 192-193). An individual actor, like all other elements, must be seen as the consequence of processes of association that allow some capacities for interaction to be expressed. We have then, what Callon refers to as the radical indeterminacy of the actor (1999: 181): the needs, wants, motivations and decision making abilities, and indeed even the form of the actor, cannot be assumed before the fact. As I shall demonstrate further on, this has major implications for the way social scientists approach medical practices.

It may seem that with this conception of the actor as a product that we have eradicated the potential source for agency. This is not so. Firstly, it must be recognised that in the monad or assemblage conception of the social, there is no ultimate source or cause for action. Action occurs when one element is made to act by another. As Latour puts it "action is not a coherent, well-rounded and clean affair. By definition action is dislocated: borrowed, distributed, suggested, influenced, dominated, betrayed and translated" (2006: 46). We can use the example of a buyer at the strawberry market illustrated above. An individual makes a decision to purchase a batch of strawberries after a careful consideration of their quality, cost of previous transactions and the price.

The individual's rational calculability that underlies their action is a capacity that has been configured by a particular arrangement of devices. Is the cause of the action, then, the individual or the electronic display board, the batch data-slips, the digressive bidding technique and the formal measurement units, without which the resultant action would never have occurred? Or is the source of the action the young counsellor of the Regional Chamber of Agriculture, an economic graduate who modelled the market on the principles of neoclassical theory? Perhaps the theory itself is the cause of the action, or the counsellor's economics professors and textbooks, or Friedrich Hayek? The point is, if we attempt to find an ultimate source of action, we are led through a chain of associations that would eventually bring us to the Big Bang. This does not mean we have no agents, however. What we have above is several points were action does not begin, but is altered or translated: textbook liberal economics is translated into a market place with a particular form by the young counsellor; a person is translated into an individual, rational buyer by the market configuration; and so on. An agent is a point where action is translated, and thus a point that has acquired a particular form in the process and puts other entities into motion: it is itself an effect of associations that comes to have an 
affect. As Latour puts it "An actor is what is made to act by other actors" (2005: 46). This brings us to the third premise of this project: By recognising that an actor is the consequence of an assemblage and not an a priori source of action, we can better understand how entities are made intelligible through translation and, therefore, how the world becomes populated with forms.

In the ontology of Tarde and DeLanda that I have outlined so far there is a conception of the society that varies substantially from that usually employed in sociology. The social is not a distinct realm embodied by the collective as envisaged by Durkheim, and social parts cannot be reduced to their relation to the whole. And society is not, as some would suggest, the consequence of the actions of individuals. Both these accounts along with the Marxist conception of society prematurely assign causation to preset agents or structures. Following the metaphysics I have adopted here, both "agent" and "structure" are the momentary effects of an assemblage that endows form upon entities through a process of translation. These assemblages are heterogeneous in that they involve associations that vary markedly: some may be medical, some may be religious and others may be legal, and so on. It is these assemblages, or monads as I have also referred to them, that constitute the social. By granting elements form and enrolling them into particular types of action, assemblages both populate the world with knowledgeable entities and put it into motion. These are the assertions of ActorNetwork Theory (ANT) and we can now see the basis for its odd allegations: if both structures and agents are the result of associations, and the macro is simply the extension and standardisation of the micro, then the social is flat: non-human elements can enrol other entities and endow them with form just as humans can, and non-human objects therefore qualify as actors. So, with these points in mind, what does this mean for the sociologist who wishes to conduct an investigation into medicine and medical practices?

Let us go back to the cardiovascular disease monad and the four accounts at the beginning of this section. Firstly, if associations are heterogeneous and there is no distinct social realm, then the ANT sociologist does not have to carve up medical practices into the "social stuff" and the "biological-medical stuff", the former being the sociologist's domain of study, and the latter being either the effect of the social stuff or the domain of the scientist. Instead, all associations are potentially open to sociological investigation. To bracket-off or prioritise some type of associations would amount to prematurely assigning form or figuration to that which is being explained. Picture 2 , the 
cellular aetiology of the disease, is potentially of as much interest to the sociologist as Picture 1, the government's response, or Picture 4, the lived experience of the disease. There has been a tendency in the sociology of medicine to focus simply on those aspects traditionally considered as "social" and ignore those that are not. Such is the logic behind the separation between "disease", deemed as the physical affliction, and "illness", thelived experience of the affliction (Mol 2002: 7-9). Along this line, some social scientists have chastised medical professionals for failing to acknowledge social elements of diseases by focusing solely on somatic elements (Engel 1981, Nettleton 1995). Whether such criticism is justified is doubtful. In Annemarie Mol's ethnography of medical practices, The Body Multiple (2002), "social” factors, such as a patient's occupation, hopes, sources of enjoyment, are often used by surgeons to assess the appropriateness of treatments for atherosclerosis (2002: 70-71). I hope to shed some light on this debate in this project.

Secondly, if complexity always escapes the standardisation and extension that produces "macro" effects, then an empirical method is necessary. An element is not fully constituted by any macro characteristics or emergent properties it may have, and it cannot, therefore, be reduced to any social function it may have or its effects on class, ethnicity or gender. In the case of medicine, although it has the capacity to affect those things usually considered as social, such as identities, subjectivities and gender, the complexity and diversity of medical practices always exceeds any attempts to explain them in these terms. Knowledge of a practice's function is not an adequate basis to understand the practice itself. This is a mistake that has often been made by sociologists. Conrad for example, has argued that medicine functions as a mechanism for social control (Conrad 1979). Medical ideology, medical collaboration, and medical technology function to eliminate deviance and insure an individual's adherence to particular norms: "by medical control I mean the ways in which medicine functions (wittingly or unwittingly) to secure adherence to social norms: specifically by using medical means to minimize, eliminate, or normalise deviant behaviour" (Conrad 1979: 1). While particular medical practices may have the effect, in some cases, of endorsing some forms of behaviour over others, Conrad's account risks reducing medical practices to their social function. In DeLanda's parlance, Conrad is suggesting that medicine is constituted by the relations it has with behavioural norms and deviance control: it is defined in terms of its function. 
Similarly, other social theorists have argued that medicine is an instrument of patriarchal control. Gena Corea, for instance, has argued that In-Vitro Fertilization is a means of controlling reproduction and therefore constitutes a mechanism for male ownership over female sexuality (1987). Again, while medical practices may, in some instances, have the effect of reducing the agency of women, the sociologists should be aware that practices are far more varied, complex and inconsistent than such an account would indicate. This is a point made clear in Mol's work, The Body Multiple (2002), based on an ethnography of the practices involved in diagnosis and treatment of atherosclerosis. She noted that even within one hospital, numerous techniques and practices are used to make sense of the disease and as a result, illness and the body are enacted in multiple ways. Rather than being comprised of a series of stable, fixed relations, medicine and disease are characterised by numerous practices that assemble bodies, patients, professionals and illness in varying networks. The result of this is an irreducible diversity and complexity that cannot be adequately defined in terms of some higher order function or ideological effect. Medicine is far from being a dominating, unified authority: it involves numerous, divergent, and sometime contested practices. If we are to understand exactly how it is that medical practices come to populate a world and provide it with motion, we are required to follow Mol's example and follow the practices as they occur, regardless of how messy the pursuit may be.

This brings us to our next commitment: we must accept the radical indeterminacy of the actor. Rather than assuming that certain entities are always actors while other entities will only ever provide conduits for action, the sociologist who approaches medicine can accept that the agents of translation can potentially have any form. The list of possible actors multiplies enormously. Not only doctors, nurses, patients, and specialists, but also nitrous oxide, macrophages, AGI-1067, and a plethora of instruments and documents may be granted the lofty status of "actor". We can see now why it is so important not to restrict sociology to an investigation of the "social", as so many agents would escape our view. This is particularly true in medicine, which, Timmermans and Berg point out, "forms an archaeology of layer upon layer of technologies from the most mundane band-aids to pencils and sophisticated machines such as MRIs and artificial hearts" (2003: 98-99). And, as Latour has illustrated in his ethnographies of scientific practice, it is often non-human objects and technologies that are fundamental components in the construction of particular facts and realities (Latour and Woolgar 1986). Instruments, like humans, have the ability to translate other entities, 
put them into motion and therefore establish an association. Keeping in mind that emergent properties cannot be reduced to constituent elements, we must also be aware that actors may vary markedly according to the traditional notion of scale: institutions, businesses, unions and ministries may also prove to be acting as a single agent. In short, the sociologist must be aware that actors can come in any form and emerge from anywhere: the test tube, a ministerial office, the sharemarket and so on.

We have dramatically increased our list of potential actors, but how do we know who or what is actually acting at any one point? If assemblages constitute the world, then uncovering which actors bring about their formation is necessary to understanding how a particular reality is brought about. The trick, then, is to uncover how others go about constructing the world, and not prematurely construct the world for them by imposing traditional sociological categories. As we have seen, the cardiovascular disease monad supervenes on an innumerable range of elements that vary in scale and form. Yet, in each one of the pictures I have provided, a coherent account of the disease has been constructed through the incorporation of a few elements and the culling of many, many more. Cardiovascular disease as a commercial opportunity is brought about through the association of AGI-1067, AstraZeneca, Dr John Patterson and an obscene quantity of cash. There is no mention of ethnicity, nitrous oxide or personal anxieties. If we wish to understand how certain realities or facts are brought about, then we need to understand how practices entwine some elements in explanations while many others become elided, forgotten, or discounted. This can only be done if the sociologist forfeits all prejudices about who and what can act, as the agents that enrol and translate other elements while obscuring most others, will become visible.

Michel Callon gives us some idea of the things we should be looking for when we are attempting to locate points of translation and the formation of associations. Firstly, a translation will always begin with an explicit definition of an entity's qualities (Callon 1986: 204-205). A set of characteristics are effectively listed; perhaps in a written account or article, via dialogue, in a graph. These characteristics are said to define the inherent nature of the entity, which is often done in such a way that grants particular actors influence over the entity or those who may wish to utilise it. Callon gives the example of three researchers attempting to remedy the depletion of scallop beds in St. Brieuc Bay, France. In written documents, they define the scallops according to several key 
characteristics: they are dredged from the sea; as larvae they are highly susceptible to predators; the larvae can anchor; the scallops are fundamentally similar to those cultivated in Japan. An entity, however, may refuse both the definition it has acquired and the list of qualities it is said to have. So, in order for the translation to occur, interessement is also necessary. Interessement is the "group of actions by which an [actor] attempts to impose and stabilise the identity of other actors it defines" (Callon 1986: 207-208). This can be done in a multitude of ways, but interessement always has the effect of putting devices in place to insure that other, conflicting definitions of the entity in question are diluted or weakened. In Callon's example, the form given to the scallops by the researchers is strengthened by the physical usage of towlines adopted from Japanese cultivation. The scallops attached to the towline as larvae, avoided predation and thus had their form asserted along with the hypotheses of the researchers. It is important to note here that it was only through the introduction of a device, an interessement device, that the scallops acquired their stable form: the material conditions of the environment had to be manipulated for the scallops to become intelligible in this way. Successful interessement, then, is the affirmation of an entity's form and the culling of other possible characterizations, and it often occurs through the introduction of additional implements. In DeLanda's terms, such implements are necessary to realise the entity's capacities for interaction. Successful interessement qualifies as enrolment: the entity has been granted a configuration and its qualities and capacities have been delimited. But if this translation is to have any weight, then other elements will also need to be convinced that the granted form is, in fact, justified. If this does not occur, then our association so far will remain isolated and insignificant, bringing about no further effects and failing to provide any meaningful facts about the world. The third moment in translation, then, constitutes the formation of further associations and involves enrolling other elements. In Callon's example, once the successful interessement of the scallops had occurred, the researchers were then able to enrol scientific colleagues. This involved convincing the colleagues of the scallop's figuration via the use of carefully prepared scientific papers (an interessement device) so that they became active proponents in perpetuating this form of the scallop (1986: 212). As Latour puts it, the more actors included and more associations that form, the more "fact" the translation becomes (1987: 108). Here we see how it is that assemblages, alliances between numerous actors, come to populate the world with knowledgeable entities. 
So far we have three movements of translation that will allow us to detect the formations of associations and the actors involved: the explicit defining of an entity, the interessement of that entity, and the enrolment of collaborators. Most visible, however, is the appearance of spokes-agents. During the ongoing translating and enrolling that takes place as entities assemble and reassemble, there are always agents, human or non-human, who claim to represent the state-of-affairs. Spokes-agents are constantly at work delineating the groups or entities they claim to represent, and this often involves the active disparagement of other, potentially contradictory groups and entities that are said to be obsolete, erroneous or dangerous (Latour 2005: 31). During the interessement of the scallops, those larvae that anchored to the towline become spokes-agents for the entire species, and the three researchers, if successful in their translation and enrolment of scientific colleagues, have become spokes-agents for the scallops and the scientific community. Obviously maintaining a spokes-agent role requires a lot of work: alliances must be kept through constant translation, interessement and enrolling, and it is this constant activity that makes spokes-agents so visible.

By noting what form an entity is given, how interessement occurs and thus how spokes-agents are able to maintain alliances, we are able to trace the formation of assemblages as they occur. We are, in other words, able to witness how it is that some actors go about populating the world and providing it with motion, while other potential associations and enactments, or capacities for interaction, go unrealised. And here we finally have a solution to the problem of quantity we keep encountering. Rather than attempting to include as many elements as possible in a sociological investigation, or prematurely assigning causality to particular types, the sociologist simply needs to follow the associations as they form and let the actors decide what elements are to be included. We may live in a messy complexity, but from this the constant assembling and reassembling of elements by various agents produces manageable pictures or accounts of the world. These pictures are often fickle, frequently disputed and very rarely become widespread. Uncovering how agents go about dealing with complexity by producing such accounts, and how some accounts may become more widespread than others, is the sociological task perused here.

Medical sociology can aim to uncover how various accounts of disease, the patient, pain, the body and so on, are produced; how it is that the complexity of the 
disease monad is dealt with through the assembling of actors and the culling from accounts of many other potential explanatory elements. The advantage of the metaphysics I have adopted here is that in tracing how these associations form, we are not restricted to any particular domain of practices. If need be, we can begin in the consultation room with the interactions between a GP and patient, move to the laboratory where centrifuges, cells, and microscopes subsist, pass through the world of corporate strategy and marketing campaigns and find ourselves back at the fleshy body of a patient. It is this agility that makes this approach so well suited to investigating contemporary medicine, which, as commentators have noted, appears to permeate so much of our understanding of ourselves and the world around us. Importantly, this approach requires us to be very specific in any investigation we may undertake. For instance, if medicine does indeed affect our conception of gender, what particular actors, whether they be individuals, instruments, molecules or ministries, associated to bring this affect about? And, how are these associations made durable so that this affect is maintained?

The strength of ANT lies in this specificity. In this project, my first aim is to uncover how an account of the body and symptoms is achieved within interactions between the patient and medical specialists and how this account is communicated. In other words, I am attempting to understand how it is that practices in medicine construct an account, and the techniques through which such an account may or may not be asserted as a reflection of "reality". By determining the moments of translation I will be able to note what actors are involved, how elements are encouraged to adopt the figuration imposed upon them, and how such associations are maintained. I will be able to determine whether or not, as has been suggested, medicine incorporates the biomedical model and rejects "social" explanatory elements, or whether the accounts produced are more nuanced than this, as has been suggested by Mol. And, if social elements are culled from explanations of disease and conception of the body, how exactly is the biomedical model realised through practices: what actors and interessement devices insure that only somatic elements are included in accounts? Additionally, if conflicting accounts are produced, how are different renderings of a seminal element dealt with?

Ultimately, these are all questions concerning the techniques of power: the power to produce a knowledgeable entity, the power to restrict other renderings of an entity, 
and the power that is the result of benefiting from a relatively durable set of associations. This brings us back to the three premises I outlined earlier on in this section. By accepting the heterogeneity of elements that constitute the social world and that the traditional micro and macro division of the social is fruitless, and by accepting that actors can come in any form, I have stated that we can uncover the specific associations that constitute power. Such an assertion requires further explanation. In the next section of this thesis, then, I will elaborate on what exactly it is I mean by the notion of power and therefore why it is such a vital concept of this project and to the sociology of medicine in general. To put it concisely, this project is essentially an exposition of what has been called biomedical power. My second aim, therefore, is to provide an account of power. 


\section{Notes on Power}

"Used, reused and endlessly abused": power, as several commentators have aptly pointed out, has been thrown around so superfluously and with such imprecision in sociology that it risks becoming an empty concept (Law 1991: 165). Nevertheless, it is not surprising that it dominates much of the literature, as concerns over inequality between various groups have provided the discipline with much impetus since its birth. Social theorists have sought to make sense of those seemingly relentless, veiled forces that sanction domination. In these terms, "power" has often been broadly perceived as something possessed and shared by an elite; a zero-sum reservoir that could be used with discretion to compel the oppressed to work against their own interests. In recent years, this crude conception of power has largely been abandoned in favour of Foucault's novel reworking of the concept (Westwood 2002: 19). Power is not simply a repressive force which we must overcome, or the barrier between enslavement and liberation; it is, rather, the very thing that constitutes us and produces us as a knowable subject. Consequently, to experience freedom is not to be outside of the relations of power, or to have overcome it, but to be engaged in the active arrogation of power for the purposes of selfformation. Freedom, truth, fact, reality: these cannot be separated from power any more than ideology and hegemony (Foucault 1977: 27). Power is a productive force, diffuse and exercised from innumerable points, allowing us to talk about, rationalise and manage things.

Unfortunately, Foucault's reworking of the concept can lead to some sloppy sociology. Power has become an explanans. In seeking to explain why the world is the way it is, why some groups are more privileged than others, some social scientists have used power as a cause, as if it constitutes some potent energy on its own, without actually exposing the specific relations and the entities involved (Latour 1986: 265). This tendency is no doubt prompted by Foucault's own constant phrasing of power as a productive force, but he also repeatedly states that it is an effect, constituted by specific relations between entities brought about by practices such as the confession, (1998: 6267) the practitioner's gaze (2003: xiv), and various disciplinary techniques (1977: 170). In this brief section I will add to the numerous sociological considerations of power and make a case for Foucault's rendition of the concept. But, in order to avoid using power as an explanans, I will suggest that by adhering to the prescriptions of ANT that I have outlined above, we can unravel the specific relations that constitute power as both a 
productive and a repressive force. I will also suggest that if power is seen as an effect of relations between elements, then relations that have become durable can result in situations where domination may occur.

So far we have seen that as associations form between elements, these elements become intelligible as their capacities for interaction are realised. Assemblages therefore construct the world, populating it with entities and providing it with actors. Is this not what Foucault refers to as the productive capacity of power?

The individual is no doubt the fictitious atom of an "ideological" representation of society; but he is also a reality fabricated by this specific technology of power that I have called "discipline"... [P] ower produces; it produces reality; it produces domains of objects and rituals of truth. The individual and the knowledge that may be gained of him belong to this production. (Foucault 1977: 194)

We have also seen that the assembling of entities and the production of intelligibility involves the culling of many other potential explanatory elements from accounts. As a translation occurs and interessement practices entwine an entity in a particular assemblage, other potential forms of the entity risk becoming discounted, ignored, or elided. An entity can be enacted by several assemblages and multiple, differing forms may exist - as Mol (2002) has shown in her ethnography of medical practices - but to be produced and delimited as a knowledgeable entity is to have a myriad of potentialities inhibited. The inevitable flip-side of a power that produces reality is restriction, or a degree of repression.

Multiple realities and differing forms of the same entity can exist and as Mol demonstrated, this is usually not problematic, particularly if the sites at which each form of the entity is enacted are kept separate (2002: 87). In some cases, however, unity is necessary. Within the hospital, a disease may have differing forms depending on which practices are enacting it, but it may be required that the "informed" patient is presented with a singular, coherent account of their affliction. Such an account is itself an achievement, the consequence of various practices of ordering and sorting, ranking and prioritising: a patient's circulating medical record, a medical student's textbooks, a health insurer's documents or a ministerial briefing, which may all portray a disease as a unified, coherent affliction, are the result of such practices. Mol outlines some of the means by which the messiness of hospital practices are dealt with. In some cases, where order and 
coherence is necessary, one reality or one form of enactment wins. A hierarchy is established and some facts are accorded more weight than others, and in the hospital it is often the account produced by the laboratory or the specialist clinic that is granted as being more factual. In Mol's example, a patient complains of considerable pain in the leg when walking - a common symptom of atherosclerosis in the lower limb. The patient is taken into the clinic, positioned on the examination table and inflatable cuffs are placed around the leg at specific points. The technician first inflates the cuffs, then deflates slowly, using a stethoscope to listen for the "popping" sound of blood as it bursts through the artificially constricted artery. Secondly, the suspect leg is subject to ultrasound probing by a Doppler apparatus. The rate of reflection of the ultrasound waves can be used to determine the rate of blood flow and can uncover any possible hindrance. The technician makes a note of the numerical outputs of both procedures, carries out some calculations, and consequently declares that there is nothing wrong with the leg (Mol 2002: 61-62). The patient's complaints become subjective, while the technician's objective findings are duly noted on the medical record as reflecting the "truth" of the condition of the arteries. Mol notes that in this specific hospital, the hierarchy between laboratory findings and the patient's feelings are institutionalised within the routine that stipulates that all clinical diseases must pass through the lab before therapeutic measures be considered (2002: 63). Despite the intensity of his feelings, the anxious, pained patient is excluded from a range of actions and resources: the assembling of a technician, cuffs, a stethoscope and a Doppler apparatus has produced a series of truths about the patient that have channelling, restrictive effects.

By undergoing the tests, the patient has become entwined in a machinery saturated with laboratory instruments, highly drilled staff and routines with very specific stipulations about who or what can be a spokes-agent and thus grant access to a further network of practices, instruments and routines. We must be aware that this machinery is never rigidly fixed; routines and spokes-agents can and do fluctuate, but nonetheless there is something durable about such assemblages, a degree of stability which tends to align particular elements in a certain way: the position of the cuffs on the patient's leg; the way the stethoscope is held against the pulsating artery; the elaborate, carefully designed mechanisms that form the Doppler apparatus. The consequence of this durability is that a great deal of the reality that will be enacted has already been encoded within the pre-aligned elements. Particular capacities of interaction will always be realised, whereas others will simply be unaffected and will either go unnoticed or 
ignored. Obviously this does not mean that a particular "positive" or "negative" result has been predetermined, bur rather that certain elements will simply never be involved in the association. The Doppler apparatus, for instance, will convert ultrasound echo and time scale into a numerical value that represents internal spaces of the body, but its design makes no allowance for, say, the ethnicity or gender of the patient or indeed the patient's anxieties or feelings. The fixed design of the internal elements of the apparatus insures that certain entities will always be culled from the account it produces. Certain capacities for interaction are therefore not realised. Herein lies the point of interest for the sociologist. Power is both productive and restrictive, and as associations can be durable, these productive and repressive effects are also encoded, prescribed, and therefore to a degree, fixed.

Foucault envisaged power as being exercised from innumerable points, which it no doubt often is: elements align and realign, actors and spokes-agents change. He is also said to have famously sullied the idea that power is something that can be possessed and used with discretion (May 2006: 82-85), but this is best understood as an injunction against simply reducing power to domination and the ability to exploit; a hindrance to liberation. Foucault's conception of power as a productive effect of various relations was more nuanced than has often been portrayed and certainly does not preclude the possibility of situations where domination may occur:

\footnotetext{
The analysis of power relations is an extremely complex area; one sometimes encounters what may be called situations or states of domination in which the power relations, instead of being mobile, allowing the various participants to adopt strategies modifying them, remained blocked, frozen... In a great many cases power relations are fixed in such a way that they are perpetually asymmetrical and allow an extremely limited margin of freedom. (Foucault 1996: 434, 441)
}

Durable assemblages, such as the example above, are the source of perpetually asymmetrical power relations. When, for whatever reason, associations become less transitory, their effects, both productive and restrictive, become more unshakable: translations become more fixed and alternative, elided potential forms and the access to networks that may have followed, become more unrealisable, less tangible. The question is, 'how is it that some associations gain durability?' To construct a stable association would require strict regulation and coordination of the elements involved: objects would have to accept their translation and their actions would have to be foreseen. Who or what could have such foresight and omnipotence? Who can create a set of relations with enough durability to bring about some form of domination? In this respect, it is 
engineers and designers who display such god-like abilities. The Doppler apparatus, for instance, is the consequence of a carefully managed alignment of metals and electric charges, arranged to have a very particular, predicted affect on air particles which are induced to oscillate at a desired frequency. This careful arrangement of elements is the consequence of years of scientific and designer trial and error, numerous attempts at translation and piles of mathematical calculation, and the result is a discrete little device, boxed-off to avoid as many unwelcomed external actors as possible, where all the elements act in symphonic precision to have a single, desired output. Technology is the closest thing to a frozen assemblage. Associations are tightly regulated so that predictable and calculable capacities for interaction of each of the constituent elements are enacted. And, if the technology or instrument is used as intended, then we can see that there will be some regularity to the accounts it produces. There is, to put it another way, durability in the way such technologies go about constructing reality.

The implications of this have been nicely demonstrated by Latour. As scientists go about discerning the nature of the world, they employ numerous instruments. Assemblages form and reform, technologies, scientific papers, lab technicians and other elements become entwined in the construction of facts. Latour notes that to have constructed or "discerned" a fact, is to have your claim tied to as many durable associations as possible. An account that has been established as a reflection of reality is an account that has been brought about by associations that are difficult to sever, that are the consequence of successfully translated elements (Latour 1987: 78). We can use Mol's example as an illustration. Let us say that the patient disagreed with the account produced by the technician and her various instruments and calculations and maintained that he did indeed have atherosclerosis in the lower limb. How will he go about convincing others, particularly his GP, that the laboratory account was wrong? He could do so by attempting to argue that the procedures and instruments he was subjected to were a waste of time and could not possibly speak truths about the condition of his arteries. To make this argument with any weight, he would have to question the engineering and scientific principles behind the Doppler apparatus, yet the challenge for the patient is that these scientific principles have been fortified by a vast collection of scientific papers, textbooks and probably most of the scientific community who have incorporated these "facts" into their own practices. These papers and practices would themselves be fortified by numerous instruments and other "facts", such as knowledge concerning the nature of particle oscillation which, in turn, are the consequence of 
numerous other practices, "facts" and instruments. The dissenting patient is confronted with what turns out to be a vast connection of well-established associations and translations that trail-off in all directions (Latour 1987: 74-79). The technician, her procedures and the Doppler apparatus are well connected, durable, and thus factual. The patient, by comparison, is unconnected, alone and his account of his leg is rendered subjective. Of course, alternative accounts can both exist without having to undergo such trials of strength, especially if they take place in quite distinct locations; but when one account must be chosen over the other, it is those that benefit from durability that will win-out.

As a strict coordination of entities, tightly regulated and controlled, technology is one means by which agents from the past or from different locations can act on the local, present-day coordinating of elements. Early $20^{\text {th }}$ century physicists and Swiss biomedical engineers have their own understanding of the world incorporated into a device such as the Doppler apparatus, which may then play a pivotal role in the enactment of a patient's body. Reality, as ethnographers point out, may be constructed and negotiated in an everyday local context again and again, but many of the important actors may be operating from vast spatial and temporal distances (Latour 2005: 200). Technology is essentially a vehicle for distant actors to act in the immediate space; encoded within technology are the beliefs and concerns of scientists and designers which, through the strict alignment of elements within instruments, have a predicted, desired influence on the production of local, immediate accounts. We can see here how technologies can bring about the repetition of similar accounts or realities, again and again. Whenever a particular technology is employed, its fixed nature ensures that the same capacities of interaction are being realised: the same range of elements are always culled from any account produced, and the type of elements that are included (and those that the instrument has been rendered sensitive to) are those that the designers have decided are essential.

Obviously the repetition of particular accounts and realities will only occur if the technology or instrument in question is used "correctly". If the instrument is not used as the designer intended, then the designer's beliefs and concerns that are encoded within it are muted. For the Doppler apparatus to produce the intended type of account of a patient's arteries, it must be used by a technician who is both highly knowledgeable about the spaces of the leg and well-trained in using the device: the Minister of Health would 
be as hopeless with the Doppler apparatus as a monkey with a violin. It is for this reason that instruments are often accompanied by instructive documents and "drilled people" (Law 1986: 255). For a technology to have an intended effect it must itself be carefully coordinated and aligned with often numerous other elements. This causes no end of headache for designers. Humans are arguably the most unruly and difficult to regulate of elements as they are forever sensitive to the actions of an enormous quantity of actors operating from all sorts of locations: somatic, local and global, historic and present. Consequently they have a tendency to engage in what Latour refers to as antiprogrammatic practices: actions that contravene what has been expected of them (1992: 261). In an attempt to coordinate human interaction with newly developed technologies, commercial institutions often spend a great deal of resources on predicting human behaviour and uncovering common antiprogrammatic practices. Findings from such research may be incorporated into an instruction manual or the design of the device in order to make it more user-friendly. The goal is to create competent users whose interactions with a technology can be predicted and regulated, so that the designer's understanding of the world is expressed through its operation in producing a particular set of effects or accounts. In this sense it seems naive to talk about technology or a particular instrument as having any effect on its own: it must always be part of a much wider machinery where various elements and actors mutually constitute one another (Prout 1996): the Doppler apparatus, its designers, the trained technician and the patient's arteries are constituted as such through their transient alignment.

We may have a carefully designed technology, but if it is not accompanied by trained personnel or at least an accessible instruction manual, then it will fail to generate the intended outcome. We are therefore far from being dominated by instruments and their inherent capacity for reproducing similar accounts, or the engineers that design them. And as Madeleine Akrich has shown in her case studies, even when technology has been successfully coordinated within a network of machines, skills and social relations, something as minute as a cotton-eating bug can quickly unravel the entire assemblage (Akrich 1989, cited de Laet and Mol 2000: 226). But despite the fragility and transient nature of assemblages, some are more durable than others. If an instrument is operated by highly trained personnel, coordinating as intended with other instruments also operated by trained personnel, and if these operating and coordinating practices are institutionalised in a set of protocols within a highly regulated physical context, then there will be regularity in terms of how this entire machinery affects other elements and 
the type of accounts that will be produced. This is why modern medicine is so exciting for the sociologist. It is characterised by large numbers of highly trained, specialised personnel, numerous instruments from the basic scalpel to the very complex MRI Technology, circulating medical records, test results and instructional documents, procedures and protocols, all assembling and reassembling in a relatively controlled physical context. As Mol has shown us in her work, protocols are seldom strictly followed: numerous assemblages may produce alternative accounts and trained personnel do not necessarily always act in a predictable manner, but modern medicine is nonetheless comprised of assemblages that do acquire a degree of durability, precisely because it is saturated with technology and trained personnel. The trained technician will use the Doppler apparatus in the same fashion on all patients suspected of having an atherosclerotic leg, and as a consequence, the same capacities for interaction are realised and the same type of account is produced time and time again. The designer's or engineer's understandings of what are the essential elements in an explanation therefore prefigure the reality that is enacted. And because these technologies are associated with a pantheon of other interconnected technologies, scientific beliefs, textbooks and practices, the enacted realities acquire an objective weight in the face of any attempted dissension. Modern medicine is a machinery of elements, seldom in accordance with one another, but nonetheless potentially dominating in that its relations gain rigidity from being encased in the material components of instruments and in the procedures of highly trained, specialised staff.

Importantly for the sociologist, what is unique about medicine is that this machinery comes into intimate contact with the bodies and body-parts of patients. As we have seen with the patient in Mol's example of the Doppler apparatus, the patient is placed in a highly ordered environment and has a very particular set of practices carried out on his leg. His leg is enacted in a particular way, certain capacities are realised, and an account is produced. We could ask: how much involvement did the patient have in this account? It was his leg and he would have to give consent for the procedure, but the result is the enactment of a healthy, fleshy artery that is, in effect, separate to the patient's anxieties, pains and understanding of himself, and it is this enactment which is asserted as being a reflection of reality. A reality has been produced by an assemblage, and the consequence is that the patient is restricted from a set of procedures and treatments that would otherwise have been available should the diagnosis have come back positive. Patients can demand to be "informed" and they are granted the right to deny treatments, 
but within the relations of the medical machinery there is often a very limited margin of freedom. A patient can always attempt to reject their enacted form, and in many contexts, outside this hospital, this may be unproblematic. But within the hospital certain avenues of action will be closed-off while others, for better or worse, will be imposed upon them. And it is often the case that the medical translations are not just medical. Diagnosis of particular pathologies, especially those concerned with mental health, carry weight outside the hospital by being inscribed in legal codes, and a positive diagnosis can severely restrict an individual's room for mobility in other areas of their life. We can see here that medical practices can come to resemble situations that Foucault refers to as "perpetually asymmetrical" (1996: 441), where the relations brought about by various medical practices have a severally restrictive impact on that which has been translated. The individual lacks the time and resources to challenge the technology and procedures involved in their enactment, and their translation is re-enacted in numerous contexts.

What makes medicine such an exciting terrain for sociologists is that this machinery, potentially asymmetrical in its various, sometimes conflicting operations, can affect those things usually deemed "social": gender, sexuality, subjectivities, social groups and so on. The so-called "medicalisation" of various aspects of human life has understandably become the focus of considerable study in the social sciences. Of interest in more recent times is how a new knowledge of genetics and molecular biology has led to new ways of self-understanding and governance (Rose 2001). This has led to the spawning of numerous bio-buzz words: bioeconomics and biovalue (Waldby 2000), biopiracy (Pottage 1998; Strathern 1999); biorisk and biosociality (Rabinow 1996), all of which reflect social scientist's recognition that knowledge produced in the lab or medical clinic often has major implications for the way individuals identify and manage themselves and interact with others. Foucault's notion of biopower is often used to make sense of this. Biopower, according to Foucault, refers to the technique of governance of the modern state, where populations are governed through various practices that subjugate bodies (Foucault 1998: 141-143). The practices of medicine and science lend themselves to this form of governance by producing a body that is equated with a life that must be "maximized" through self-surveillance and self-management. Governance therefore involves promoting individual self-responsibility, and "freedom" is understood in these terms. Much of this interesting work on biopower does appear to provide a coherent explanation of the interrelationship between liberal governance, bodies and medicine, but it is often problematic. It tends to overstate the domination of medicine 
by assuming that the categories, terms and narratives of science and medicine are naively adopted by an eager population of individuals. There is very little elaboration on the specific relations that might bring these effects about, and any material relations are often dismissed in favor of discursive or "social" forces. Medicine is rendered as something of a leviathan, the source of new knowledge, categories and subjectivities that risk spreading throughout the modern world with the momentum of an epidemic. As a consequence, many of the actors involved in the relations that constitute biopower are completely overlooked, and so are the numerous cases where medical categories and diagnoses are contradicted, are treated as irrelevant or are out-rightly discarded in favour of other means of self-identification (for an example of this, see Callon and Rabeharisoa 2004).

If instead we see power as the effect of relations between elements, then we can avoid these pitfalls. To possess the capacity to produce or repress, as John Law puts it, is to enjoy the effects of a stable network of relations (1991: 166). In order to comprehend power it is therefore necessary to understand how networks come about and recognize that these relations are heterogeneous: they can be material, such as the alignment of elements in the Doppler apparatus, legal, social and so on. By adhering to the ANT principles outlined above, we can follow relations as they form, note how entities are endowed with various figurations and reveal how it is that some relations and translations gain a degree of durability. Firstly, this approach has the benefit of drawing our attention to the numerous instances within the medical machinery where ontology is multiple. As we have seen in Mol's ethnography of medical practices, an entity's form is not bounded or fixed; it is fluid and multiple forms do not necessarily lead to confusion or conflict. And secondly, this approach will allow us to understand, when conflict between forms does occur, how it is that one account or translation is asserted over others. In other words, the strength of the method I am adopting for this project is that it reveals how a relationship between various elements is brought about, how this relationship can produce an account or a reality, and how the reality produced may have restrictive or repressive effects. And in terms of comprehending power, this is a method well suited to exposing relations that have become fixed in such a way that they result in a perpetually limited margin of freedom for particular actors. As we have seen, it is necessary to recognize the important role of technology in bringing about durable or fixed relations. It has the capacity to bring about similar accounts again and again, and because instruments are often interconnected with numerous other technologies, practices and documents, the accounts they produce are often equated with objectivity. 
It is this recognition that such material relations and non-human actors are often vital components in bringing about those "social" effects that makes ANT so well suited to the study of technology-laden medicine, and from a theoretical point of view, it provides an excellent foundation for understanding how power can be both productive and repressive, and how, in some cases, it constitutes a relation of domination.

\section{A Restatement of Points: Associating with the Data}

After our lengthy elaboration on the ontology of ANT and the relations of power it is useful to restate the key points. The primary aim of this project is to understand how it is that medical practices go about producing accounts from monadic complexity: how it is that some elements are brought into medical ontology while many others are ignored, disregarded or elided. I will be focusing specifically on the practices involved in the diagnosis of a particular patient. My intention, then, is to uncover how a particular diagnosis is achieved, and how this is asserted as being "objective", or a "true" reflection about the state of the world. In order to provide some analytical coherence to this undertaking, I will roughly adhere to the following points provided by Callon (1986):

- Translation. Translation occurs when an entity is said to have a set of qualities and it is granted a particular form. Here we are searching for points where the diagnosis is explicitly defined, perhaps in a written document, an illustration or via conversation. The diagnosis is based on particular qualities that the body or body-part is said to have and which are therefore treated as reflections of its real nature.

- Actor Identification. The qualities that an entity is said to have are brought about through associations with other elements. A diagnosis is therefore made through the realization of particular capacities of interaction within the body or body-part, and these capacities of interaction are realized through the interaction of associating elements or actors. It is important to note not only what form the body or body part is granted but also how the associating actors bring this about. At this point we will be mapping the immediate assemblage involved in the enactment of the body or body-part. 
- Interessement: The formation of an assemblage and the construction of knowledge from complexity involves the culling of many other possible explanatory elements from the accounts produced. Interessement is the group of actions which prevent other potential forms of the entity from being realized and consequently stabilize the intended translation. These group of actions often involve the use of material devices which have the effect of reducing the likelihood of alternative assemblages forming which would result in the realization of different capacities of interaction and thus a different enactment of the body or body-part. Here, then, we are searching for those instances where the patient is situated in such a way that there is marginal room for alternative ways of making sense of their body or body-part.

- Enrolment. In order for the translation of an entity to have any consequences, other actors must also be convinced of the qualities that have been attributed to it. More entities must become associated if the assemblage is to construct any meaningful information about the world and avoid becoming insignificant. We must therefore note how it is that other actors, both human and non-human, become convinced of the diagnosis and thus enrolled in the translation. It is through these resulting alliances and interconnections that the diagnosis acquires "objective" status and is asserted as a true statement about the nature of the world.

- Spokes-Agents: During the formation of assemblages, certain actors are constantly at work delineating the groups or entities they claim to represent, often actively deriding other, potentially contradictory groups or entities that provide alternative accounts. Spokes-agents, like all actors, can be either human or nonhuman. Here we will be identifying those elements that claim to represent the real nature of the body or body-part during the diagnosis and are therefore actively engaged in delineating the patient and their illness.

These points provided by Callon will not necessarily represent distinct, separate operations: it is quite possible that translation, interessement and enrolment might be brought about by a single spokes-agent at a single instance. These simply provide a rough guide enabling us to makes sense of the constant assembling and reassembling of elements by drawing our attention to specific instances where action brings about the formation of knowledgeable entities. Following Mol (2002), I will make extensive use of 
the term enact. The advantage of this word is that it conveys something of the temporality of translations. Unlike "construction", which tends to suggest the creation of something that becomes stable and fixed, "enactment" alludes to the potential fragility of the form that an entity is endowed with. An entity can acquire a meaningful form in a particular time and place, but this may soon be disregarded, ignored, forgotten or superseded by another enactment.

What we are effectively producing is a map of medical practices as they populate a world; a map of an assemblage as it enacts a reality. The map that we create cannot possibly articulate the near-infinite amount of detail that characterizes all phenomena, but if we hope to avoid prematurely assigning causation, we must nevertheless attempt to explicate all those points of translation that are essential to the assemblage we are following. As McGrail puts it, a good ANT map will always be stubbornly situated: "performing its terrain well for some purpose without becoming a general model waiting to swallow up distant settings or implying undue relevance to 'Cleopatra's nose' ${ }^{3}$ by blindly following actors" (McGrail 2005: 129). Drawing attention to the points of translation, and the practices of interessement, enrolment and the activities of spokesagents should insure that our map of the medical practices involved in a diagnosis is sufficiently detailed while remaining void of unnecessary, banal detail.

There are some general statements that I wish to deduce from this map, however, concerning the nature of power. Once we have traced our assemblage, we will have an illustration of how relations between elements produce a reality, how this production can have channeling, restrictive effects, and we may also have an illustration of how relations become durable so that they "allow an extremely limited margin of freedom". I am hoping, then, to show that power is an effect of various relations between elements, and not a force on its own, an explanans for social phenomena. There is a political motive to this. This project is essentially a description of how others go about constructing and negotiating a reality, how facts are deciphered from non-facts and how one account comes to be viewed as more objective or truthful than others. If we can expose some of the techniques through which this happens, then we are well placed to impede relations that constitute domination, should there be an ethical or political

\footnotetext{
${ }^{3}$ Marc Antony was said to be so transfixed by a marble bust of Cleopatra that he was tragically late for the decisive battle of Actium. Pascal argued that had Cleopatra's nose been smaller, the battle would not have been lost, and western history would have unfolded otherwise.
} 
imperative to do so. To put this succinctly, if we have an understanding of how domination can occur, then we are obviously better suited to undertaking effective counteraction. 


\section{2 - Medicine in Action}

In mapping our assemblages we will be following a patient on a foray through the healthcare system. Fortunately for the patient and us, this does not require the awkward presence of a sociologist in the consultation room, taking rushed and clumsy notes. This work has been delegated to a much more reliable and less invasive set of actors, video and audio recorders, which have been set-up by a research nurse in locations where the interaction between the patient and medical specialists/instrumentations took place. Our patient, Simon, began his venture with a consultation with his GP, who then referred him to a specialist to undergo further testing. This has generated three distinct sets of video and audio data, each corresponding to a different location where action took place: the GP consultation (location 1), the test (location 2), and the debrief with the specialist (location 3). Following suit, this chapter is divided into three sections. The first two sections deal with what are effectively two discrete sets of practices enacting two discrete accounts, while the third deals with an attempt to coordinate these accounts. 
In location 1, we will be tracing the elements involved in the enactment of pain. I will show, following Mol (2002: 23-27), that it is through interaction between the GP, the patient, and various other elements that pain acquires a coherent form. In location 2, we will watch the patient as he is assembled amongst a series of instruments, resulting in the construction of an inscription device which produces an account of the internal spaces of the patient's body. The construction of this inscription device and the subsequent account is the result of the careful alignment of elements brought about by a medical technician and a specialist. In location 3, we will witness an attempt by both the specialist and patient to make sense of the inconsistency between the account of pain produced in location 1 with the account of the internal spaces of the body produced in location 2 . These accounts are potentially conflicting, and two tactics are used by the specialist to provide a sense of coherence. Firstly, he provides an alternative explanation for the pain which is consistent with both accounts, and secondly, he questions the reliability of the inscriptions device and therefore the account of the internal spaces of the body. No final, absolute diagnosis is made, however. I will argue that as a result of this, in location 3 we have the enactment of an indefinite, vague reality: a body part that is most likely healthy but still a cause for concern.

It is necessary here to give a brief explanation of my method of analysis. Firstly, video recordings of each of the three interactions were observed several times, and points where translations occurred were noted. Transcripts of these points were then examined, noting which elements were brought into the production of accounts, and which actors were involved. These were then checked again with the video recordings to insure that all necessary actors and elements had been identified, particularly those that may not have been expressed in verbal conversation. Excerpts of the transcripts have been provided throughout the following sections. I have made very minor changes to these excerpts to improve readability. All video data and transcripts were prepared by the ARCH research team. 


\section{Section 1: Enacting Pain}

Location 1 is the setting for the patient's primary consultation with his GP. The room is much like any consultation room: the GP's desk is against the wall, upon which sits a computer, some medical reference books, a couple of ring binders and some paper notes; two chairs for patients are next to the desk; alongside is an instrument for measuring blood pressure; and on the other side of the small room is a narrow bed with a pillow. This arrangement allows the GP to swivel easily from facing his patient to his desk and computer. Our patient, Simon, is concerned about pain that he has been feeling in his chest. Our consultation begins with Simon taking off his jacket, and taking a seat. He and the GP then begin to discuss the pains he has been experiencing. The result of this discussion, as we shall soon see, is the enactment of chest pain: Simon's chest pain becomes a coherent entity with a set of particular qualities, and as a consequence of this, it becomes an actor in-itself. Before we begin, however, it is worth having a brief overview of pain as an item of sociological study in order to provide some theoretical context for the following discussion.

\section{A Sociology of Pain}

No doubt it seems unusual to suggest that it is through interaction that pain becomes an entity: surely the physical pains of the body can exist and be felt regardless of any attempt to articulate them and certainly prior to engaging in any medical practices. These points are not being denied by claiming that pain is enacted in the consultation room. What I am suggesting is that during the consultation process, the bodily-sensations experienced by the patient must be communicated to the GP in some form or another, and this requires the construction of an account by employing various explanatory elements. The patient is by no means the sole creator of this account, as the type of explanatory elements used will depend a great deal on the questioning and investigative techniques of the GP. It is through interaction, therefore, that bodily-sensations become something that can be talked-about, and thus something that is the basis for further action, and it is in this respect that it becomes an entity that it was not before.

In characteristic fashion, social scientists have chastised medicine for reducing

pain to a series of neurophysiological events, ignoring any sociological and 
phenomenological factors (see, for instance, Bendelow and Williams 1995). Yet, if we look at Mol's work, pain in the consultation room is often understood in terms of social considerations: the inability to walk certain distances, or the inability to climb four flights of stairs to a daughter's apartment $(2002: 14,22)$. It is from these sorts of details that pain becomes a coherent entity, and upon which decisions about treatment plans are made. It is certainly not limited to a series of somatic events and there is room, then, for accounts of pain to take a range of forms by including a variety of explanatory elements.

A nice example of the composite, indefinite nature of pain is illustrated in Nettleton's historical overview of dentistry. Within dental practice and literature, the meaning of pain has changed, corresponding to changes in what Nettleton refers to as the "spatial locations" in which the objects of dental practice reside (1992: 65). Prior to the Great War, pain simply did not exist: dentists were trained to manipulate the mouth without regard for the feelings of the patient (1992: 66). By the mid 1930s, however, the "feeling" patient emerged. The object of dentistry was now an individual with a body and mind, and dental practice altered significantly to reduce or avoid pain. Pain was conceived as a physiological problem, located firmly in the fleshy body of the patient (1992: 66). After the Second World War, dental practice began to include social aspects in definitions of pain and fear: disease and pain were not simply phenomena of the flesh, they had "subjective conditions" which were the product of "genetic, familial and environmental background" (1992: 68). As Nettleton puts it, "dentists were made aware that they were treating humans, and not just teeth" (1992: 71), and dentists were told that the success or failure of a treatment may depend more on the rapport they had with the patient rather than on their technical proficiency (Nettleton 1992: 71). By the late 1950s, dental practices were centred first on discerning the nature of pain and then on its elimination. Dentists were instructed to systematize their practice with a series of standardised questions for patients, concerning: the exact location of the pain; the presence of any other accompanying symptoms; the character of the pain (ache, dull, and so on); if there was anything associated with the pain, such as high or low temperatures or eating particular foods; and finally on the duration of the pain (1992: 72).

Pain went from being something invisible or inconsequential in dentistry, to something that existed in the fleshy body and to be avoided in successful dentistry. By the 1960s, pain was the object of considerable attention when consulting with patients. As Nettleton states, as dental practices changed, so did the attributes of pain. It was both the concern and the product of practices, aimed at discerning the nature of, and the 
elimination of pain (1992: 65). In effect, as dentistry progressed, a space for pain to exist as an entity opened-up, and the specific explanatory elements that could be used in an account expanded from almost nothing at all, to physical causes and to eating habits. Although Nettleton's genealogical approach differs from the approach being used here, it does illustrate some of my points. Firstly, as we have seen, pain as an entity in the consultation can potentially take a range of forms. Two patients may experience similar bodily sensations, but if the interactive practices within their consultations differ markedly, then so may the pain that is enacted: the elements brought into an account are by no means determined by the patient alone. Secondly, as a consequence of this, the nature or explanatory elements brought into an account are often heterogeneous. Making sense-of pain is not limited to neurophysiological causes and eating food, life-histories and visiting the daughter can be valid explanatory elements, particularly in a profession that aims to treat the patient as a human as well as a body.

Keeping these points in mind will aid us in the pursuit of tracing the enactment of Simon's chest pain. Our intention is to note what elements, whether they are somatic, social, psychological and so on, are brought into the account of pain, and what practices bring this about. To reintroduce the terms defined in the previous chapter, it is via elements or associating actors that chest pain is translated, acquiring an intelligible form. In the process of identifying the practices involved in the enactment of chest pain, we will be noting the spokes-agents, those actors that are constantly delimiting the elements and the attributes of pain as they are defined.

Before we begin with our consultation, it is necessary to reiterate a methodological precondition. It is tempting to treat pain as a symptom, the result of physical events in the body, and as something which subsequently has implications in terms of how the patient can then carry-out their normal day-to-day activities. This would allow us to divide our elements into the physical causes of pain (the "disease"), and the social and psychological repercussions of having pain (the "illness"). But if we do this, we are prematurely granting pain with a form, rather than tracing how pain is given form in practice, and thus rather than looking at how others go about enacting worlds, we would be jumping ahead and constructing a world for them. It is necessary, therefore, to discard any prior assumptions about what sort of elements should be granted that status as "cause" and which should be relegated to the status of "implications". If any such division is made, it will be the result of the explicit sorting and ranking practices of spokes-agents, which we will be able to trace. In this section, 
then, we will focus solely on the translating activities of actors and refrain from imposing any prior assumptions about the nature of pain. We must approach the consultation with as much impartiality as an anthropologist studying an unknown community and let the practices of the participants reveal their unique world. By adhering to this "follow the actors" approach, we will see how it is that pain is actually articulated in the consultation and how it is that understandings are negotiated, order is produced and thus how further actions come about.

\section{The Consultation}

I - Interactive construction

We have a patient, Simon, and a GP. Before the interaction begins, we can assume nothing else about what actors will come into play and what entities will be revealed. No doubt both Simon and the GP enter the consultation with a vast set of their own assumptions about the nature of the pain, disease, illness, and the body, and with a set of understandings about how the consultation should be conducted, but unless these assumptions and understandings are revealed in practice, they are of no concern to us. A large part of the action within the consultation takes place via conversation between Simon and the GP, and it is through this verbal interaction that many of the explanatory elements are brought into the account of pain. As the conversation takes place, things that exist outside the consultation room, or things that may have occurred sometime ago, are brought to bear on the immediate assembling of entities involved in the enactment of pain.

Initially, most of the talking is done by Simon as he explains his pain to the GP. He begins by qualifying the pain as a "tightness across the chest", and then goes on to provide further detail:

Simon: At times when I'm under stress I get this tightness across my chest and it's quite uncomfortable. It is slightly complicated by the fact that about three weeks ago I was going to shift a fridge. But I didn't notice any, like, I had damaged myself, but I wondered at that stage whether I had kind of pulled some muscles... In fact, just this last night I woke up in the middle of the night and was angsting about something and it felt kinda tight and uncomfortable 
and its not shooting pains or anything. It tends to move around a bit, but probably tends to be this side [Simon places his hand on the right side of chest].

This is the account that Simon gives of his pain prior to any major leading or questioning by the GP. We can see that an assortment of elements is brought into the account: the shifting of a fridge, pulled muscles, stress and anxiety, broken sleep. Some of these elements are somatic, others are clearly not. Simon obviously associates the painful sensation with feelings of anxiety and stress, but it is also linked to physical exertion and the pulling of muscles: it has both psychological and physical associations. The pain is granted a rough location: the chest, predominantly towards the right, but it does move around. And it has also been described as a certain type of sensation: "tightness", rather than "shooting". Already with Simon's preliminarily rendering of his pain, we have an entity that is becoming intelligible as it is granted attributes. Yet, aside from suggesting a couple of reasons for the pain, he has by no means made a firm assertion concerning its cause, and it still remains a vague, hazy entity. It is not formless, but it does not yet have any solid form.

Up until three minutes into the consultation, the GP has said very little and as a result has contributed very little to the account of chest pain that has so far been produced. This changes as he begins to ask a series of questions in order to further discern the nature of the pain:

\section{GP: Going back to your family history is there anything you think we need to know about?}

Simon: Mum had heart attacks. It would have been at probably a similar age to me. My Father lived till eighty five or six. It wasn't a heart problem for him.

GP: Okay. Between last time you saw a doctor almost a year ago, you have had some other episodes as well.

Simon: Yeab, yeah. It could have been maybe two or three in that period of time.

GP: What about with exertion and exercise, any problems there? 
Simon: No. Well, I don't get a lot of that [exercise], no more than walking or going down my steps. I don't run or anything. My ankles are knackered, I can't run anymore.

GP: Okay. Associated with the discomfort, is there anything else like nausea or feeling of your heart beating fast, or sweating?

Simon: No, none of that. It's just discomfort.

GP: Any discomfort spreading to the right arm, or into the neck and throat area?

Simon: No.

We can see here that with this succinct line of questioning, a range of new elements have been introduced. Firstly, family history is brought into the interaction and Simon's pain acquires a genealogical component. An association is made between Simon's pain and his Mother's troublesome heart. Secondly, the pain acquires a frequency of occurrence: between two and three times in the last year. Thirdly, the pain has been understood in terms of exercise. Although, according to Simon, the pain does not occur during exercise (which in his case is no more than walking or using his steps), exercise has become an explanatory element; a means by which pain is made sense of, and it has therefore become part of the account. The same can be said regarding the feeling of nausea, the sensation of a fast-beating heart, sweating, and pain in the arm and neck: Simon's pain is made sense of in terms of the explicitly stated absence of these elements.

Simon's pain, then, is acquiring more form. As more associations are made, and more entities are brought into the account, the more intelligible it becomes: it has some qualities, it lacks others. It has location, it occurs in the chest, not the arm or the neck. But it is not restricted to Simon's body, as it also potentially exists as a familial phenomenon, in the body of his mother. It has tentatively taken on a hereditary dimension. It has also acquired a temporal dimension, and can be understood as something that occurs, or has occurred, with a certain frequency: It has been situated in time. And, it is understood as something that is not linked with several other bodily sensations.

It is clear here that the pain enacted in the consultation, the pain that is intelligible, is the consequence of interactions which involve local, shared negotiations. 
Obviously the form that pain takes depends not only on how Simon articulates his bodily sensations but also on the specific questions asked by the GP, and these questions both reflect and enact an understanding about what particular capacities of chest pain should be enacted or made known. We can assume, then, that the GP's questions reflect his understanding of chest pain-as-a-symptom and its possible causes, where family history, nausea and spreading pain are considered essential indicators of a pain's underlying cause.

It is worth pointing out here that there is a degree of shared understanding between Simon and the GP. The first question put forward by the GP; "Going back to your family, is there anything you think we need to know?" could, in another context, lead to an enormous number of responses. Yet, in this consultation, Simon has understood this question as something along the lines of "does your family have a history of heart problems?", and has responded with: "Mum had heart attacks, it would have been at a similar age to me." The GP assumed that Simon would understand this question as referring to a history of heart problems, just as Simon assumed that this is what the GP meant. As a consequence of the tacit understanding, "The heart" and "family history", which were both absent from Simon's initial account of his pain, have promptly been added as explanatory elements.

At this stage it is clear that both Simon and the GP are major actors in the enactment of pain as a knowable entity. Both are involved in bringing certain elements into the account while leaving others out. While the GP is directing which type of elements are to be included through his line of questioning, Simon has been generating associations both in his responses to these questions and in his initial rendition of his pain. We can employ some of our ANT terminology here and say that both these actors are involved in translating chest pain, from a bodily sensation into a clinical entity. In this case, chest pain as a clinical entity is composite: it involves heterogeneous explanatory elements, from shifting fridges and broken sleep, to hereditary heart problems and an absence of nausea. Borrowing one of Mol's terms, this chest pain is very much a "patchwork singularity" (2002: 70): It is being discussed as if it is a singular, discernable entity, yet it is being patched together using elements that are somatic, social and psychological. 


\section{2 - Fluid translations}

This patchwork entity is by no means yet fixed. As the consultation progresses, we will notice that some of the explanatory elements are foregrounded as being potentially more explanatory of the pain, while others escape further mention. The translation of chest pain, then, is ongoing. What we do find, however, is that the entity, as it has so far been translated, has become the basis for further action. It has become intelligible enough that decisions can be made about what avenues of action should be taken, and in this sense it has become an actor-in-itself: it is not yet fixed, or rigid, but it has attributes, and these attributes are sufficient grounds for bringing about a further set of associations.

GP: Obviously, the pain, we worry about it. You worry about whether it is coming from the beart and obviously that's the important thing to rule out because some people only get so many warnings. So, slip your sleeve up there. [Here the GP begins to check Simon's blood pressure.] What I think we need to look at doing regardless of what I find, the chances are the examination will be normal, is to send you off to run on a treadmill for a while, wired up to an ECG and do a stress ECG, which is a cheap and easy test to do and which has a pretty good pick up rate for a heart that's not getting as much oxygen as it wants. .. Yeah you're right, your blood pressure is always good, similar level to what it was last year. Now, you're a non smoker. Have you always been a non-smoker?

Simon: Nah, I stopped, ob it's been a while ago, it would have been early eighties when I stopped.

GP: Okay. Were you a heavy sort of pack a day man? How long would it have been for?

Simon: Yeah. All of my adult life at that point really.

GP: Slip your shirt off and I will have a listen to your chest.

Simon: One of my colleagues at work suffered from a cardiac last week, and had an advanced heart rate. It kind-of brings it to the consciousness a bit.

A new set of elements has been introduced. The GP has introduced an association between chest pain and smoking, and smoking has been made sense of in terms of 
quantity of cigarettes smoked, and duration of smoking. Aside from this, we see the foregrounding of the "heart:" and "cardiac" as explanatory elements. The GP states that the heart is the "important thing", and it is therefore necessary to undergo a treadmill test in order to determine "if the heart is not getting as much oxygen as it wants". "Oxygen", and a "heart-that-requires-a-certain-amount-of-oxygen", have become explanatory elements.

As a consequence of this translation of chest pain, a series of further actions are undertaken, each involving the assembling of new, mostly material elements and the enactment of new entities in the consultation. Simon's blood pressure is measured, for instance. An inflatable cuff, attached to a manometer, is fitted to Simon's arm at a specific location, inflated and then slowly deflated by the GP who, using a carefully placed stethoscope, listens for the characteristic popping sound of blood as it passes through the artery. The result of this careful alignment is the generation of a couple of numbers which represent the systolic and diastolic blood pressure. Here, elements are brought together, particular capacities of the body and equipment are enacted, and "blood pressure" is rendered as a couple of meaningful numbers. The value of these numbers allows the GP to remark that Simon's blood pressure is "good", and the actual numerical values are noted in the medical notes which we will come to soon. Similarly, the GP "listens" to Simon's chest. Again he uses a stethoscope, and again a careful alignment of elements results in the enacting of particular capacities within Simon's chest, resulting in the production of meaningful information. Each of these practices brings a new series of elements into alignment and brings new, intelligible entities into the consultation. Obviously the capacities that can be enacted by such assemblages are pre-figured by the fixed, designed nature of the apparatuses used and their careful alignment, coordinated by the GP, with Simon's body. We will come back to this point in section two.

The "cardiac" and "heart-that-requires-a-certain-amount-of-oxygen" link that has been established with Simon's chest pain also brings about two further courses of action. These take place outside of the current consultation. The first, as noted above, is the treadmill ECG test, which is the subject of section 2 of this chapter. The second is initiated as follows: 
GP: It is probably worth doing a blood test. We have this test called Troponin T, which is helpful. It's a chemical which is released from unhappy heart muscle cells, basically if they're a bit under stress. It rises dramatically in heart attacks.

A blood test is suggested, and in the process we have the introduction of more explanatory elements: "Tropinin T", and "unhappy-heart-muscle-cells". The results of this test are, at a later time, recorded on the GP's medical notes.

We can see here, then, how chest pain is constructed as an intelligible entity and subsequently becomes the basis of further action. Through interaction between the GP and Simon, various elements have been assembled to produce an account of chest pain. As we have seen, this chest pain is composite, as it includes a range of heterogeneous explanatory elements. And it is certainly not fixed, more associations are made, some associations are foregrounded and emphasized, and others seem to fade into the background: the translation, then, is ongoing. But, despite this lack of solidity, chest pain has acquired enough attributes (often only through tentative links) to instigate particular courses of action, each of which involve the assembling of material elements and the production of more intelligible entities. In this consultation, then, we have a snap-shot of world-building. Action is bringing about the enactment of entities, which then bring about further action: an order of things, not fixed or definite, but nonetheless utilizable, is being created, assembled, and employed.

\section{3 - Probability as intelligibility}

So far we have seen the foregrounding of the "cardiac", and "heart" elements of Simon's chest pain, and how this has led to the treadmill ECG stress test and the Tropinin $\mathrm{T}$ test, and the measurement of Simon's blood pressure. The GP, however, then goes on to make a tentative diagnosis:

GP: If I were a betting man I would put my money on the fact that this certainly is not heart related. I suspect it's coming from the chest wall but I can't be a bundred percent sure and I think it is such a straight-forward test to do. 
GP: Yeab yeah. I do think we should look at doing it because there is a chance; the past bistory of smoking, the family history, we need to take those into account.

$\backslash$ Here, an unhappy heart is not being foregrounded as the most probable cause of the chest pain, but rather as an unlikely, but highly dangerous probability that requires exploration. This probability, although minor, is the consequence of the "smoking" and the "mum had heart attack" links to Simon's chest pain that had been made earlier, and, according to the GP, are sufficient grounds for further testing. As the most likely causal element for the pain, the GP introduces the "chest wall".

It is worth commenting here on the GP's strategy during this consultation. Simon, in his initial rendering of his pain, makes no mention of his heart, his family history of smoking, or family history of heart problems. These explanatory elements, as we have seen, were quickly introduced with the GP's line of questioning, while many of the elements that Simon put forward, such as "angsting", "stress" "pulled some muscles" have so far been ignored. The GP's primary strategy, as he puts in his own words, has been to "worry about whether it (the pain) is coming from the heart... that's the important thing to rule out". No doubt this concern for the heart, and the line of questioning used to discern the probability of the heart as a cause, is a reflection of his training and previous experiences, and we have seen how Simon's chest pain has been made intelligible as a consequence of this concern. The result, as we see above, is that the chest pain that has been enacted is not fixed or absolute, but composite, fluid, and as potentially dangerous: it is intelligible in terms of probabilities and risk, and as something that therefore requires further exploration.

\section{4 - The product of differing concerns}

Once this tentative diagnosis has been made and several courses of action have been decided upon, the consultation continues with Simon elaborating on his earlier account of his chest pain. 
Simon: But I think my depression rate is getting worse. [A close relative] died a couple of years ago, I don't know if I mention that, and yeah, other complicating factors, my son's finally left home and I can't quite get over that - I think probably there's more episodes [chest pain] these days. So I guess I sort of angst about things more than I used to.

GP: Do you get to the point where you get broken sleep regularly or affects your appetite?

Simon: Nah, never affects my appetite. It can affect sleep, certainly.

GP: Any kind of life isn't worth living type thoughts?

Simon: No no no. Just more about, you know, kind of self worth and your place in the bistory of things, what you've done in your life and maybe the fact that I'm coming up 60 and you tend to look back over what's been a bit of a rocky road. Yeah, so, I don't know if that's got anything to do with it.

Simon leads the consultation away from talk about the "heart" and reintroduces some of the elements that appeared in his initial account, notably "angsting". The death of a relative, his son leaving home, worries about self-worth, have also been brought in to the interaction: Simon has directed the consultation towards a new set of social and psychological concerns that he thinks may have something to do with the "episodes" of chest pain. Again, some sets of elements are being foregrounded while others, this time heart related, move into the background. And again the GP responds with a series of direct questions, bringing "appetite" and "sleep" and "life isn't worth living thoughts" into the interaction. The GP goes on to state that:

GP: Yeah yeah. Well, this may be relevant to what's going on [chest pain] of course. Two thoughts come to mind, one is whether medication will be helpful and the other is whether some kind of counselling would be helpful.

And later:

GP: I guess from what you have said it is probably more, as you say, that kind of existential sort of stuff [that is causing this], and as well the sort of grieving stuff you are working through. 
Here we have moved towards an enactment of chest pain as being caused by feelings of anxiety and stress and worry. Again, the language the GP has used reiterates that this diagnosis is only tentative.

At this point, it is worth briefly retracing the consultation. We began with Simon's, initial account, which included links to "angsting", "moving fridges" and "pulled muscles". The GP responded by directing questions towards the heart, family history, and then towards smoking. From this, chest pain was constructed as something that may be heart related, and based on this, a series of tests were initiated. Simon then directed the interaction, as we have just seen, back to psychological elements: "angsting" was foregrounded, as was "stress", "self-worth" and "depression". The enactment of chest pain in the consultation is the product of interaction between two principal actors, Simon and the GP, but it should be noted that each actor appears to have had different concerns. Aside from Simon's comment about his work colleague who "suffered a cardiac", he has not initiated any verbal links with his chest pain and the "heart". These links have all been initiated by the GP. The GP, on the other hand, has played a very minor role in introducing psychological elements; this has largely been directed by Simon. The different concerns no doubt reflect the different experiences of the two actors, and in the case of the GP, institutionalised training. We could say that both actors have been moved or affected by varying sets of other actors to focus on particular associations by asking certain questions and viewing some elements as more explanatory than others. And these different concerns do not, as we have seen, lead to any explicit disputes concerning the nature of pain, but rather contribute to constructing a chest pain that is composite and fluid as different associations are foregrounded and others fade away.

\section{5 - Consolidation}

So we have seen that within the consultation, interaction has generated a composite, indefinite chest pain, intelligible in terms of probabilities and risk. And we have seen how this enactment of chest pain has led to a series of actions, each involving a new assembly of elements and the enactment of more intelligible entities. But what happens when the interaction between the two principal actors ends, when the negotiations and assembling 
ceases, does this chest pain have any sort of existence as an intelligible entity outside the consultation? In our case, some of the details of the interaction have been recorded by the GP in his medical notes, and it is this record that provides ongoing durability to Simon's chest pain outside of the clinic. These notes, then, effectively represent the final translation, a consolidation of the chest pain that has so far lacked solidity. As a written document, the explanatory elements presented within it are fixed, and are not subject to the ongoing foregrounding and fading that we saw taking place during conversation: the ongoing, moulding translation of the interaction is therefore rendered as something that is fixed and stable within the GP's notes. Below is a summary of the GP's notes. In order to provide as much anonymity to the patient as possible, I have replaced some of the specific details with more general information.

\section{Medical Notes}

Presents today with a further episode of chest pain up to $45 \mathrm{~min}$ in duration at 0400 woke. No assoc. nausea/sweats and no radiation to arm and neck. Minor niggles also between last year's episodes and today. No external pains noted: tho only walks these days. No SOB arrhythmia noted. Note: fam bx - mother developed IHD late 50s. Smoked 20/d for approx 20 y. from 20-40. Admits some stress \&o mood upsets which he thinks may relate to son leaving home. Also, upcoming anniversary of death of close relative. Troponin $T$ and blood pressure are normal.

It is important to note how the events of the consultation have been recorded, particularly which elements have been included and which have been discarded. This will give us some indication of which explanatory elements explored in the consultation are viewed by the GP to be essential to Simon's chest pain. As we can see in the notes above, this fixed translation of chest pain is still composite in that it incorporates elements that are somatic, social and psychological: Troponin $\mathrm{T}$, the mother's troublesome heart, the absence of pain in the neck and arm, the duration of pain, broken sleep, smoking, the son leaving home, stress, and the death of a loved one have all been included in the notes as potentially essential to understanding the chest pain. Here we see, then, the product of both the GP's concise line of questioning that led to the inclusion of the smoking and family history elements, and Simon's account, which includes references to his son, and the recent death of a relative. What we don't see however, are references to pulled muscles, shifting the fridge, appetite or the chest wall. 
Some elements have been culled, and others have been consolidated within the written account, and the GP, who creates this written account and has the ability to amend them at a future date, is a spokes-agent for the chest pain.

The importance of these types of notes and records is that they allow the consolidated entities of the consultation to act across temporal and spatial distances. The record presented above, for instance, will be consulted in the future and the information contained within it may become the basis for more action. Records and notes are often circulated to other locations, and in this case, the notes were forwarded by the GP to the cardiac specialist responsible for conducting the treadmill stress test that we will be following in the next section. Consequently, Simon's chest pain, and Simon-as-a-patient attain an intelligibility that extends through time and escape the immediate location in which they were originally constructed. The translation, then, becomes durable and mobile.

\section{6 - Multiple preoccupations}

Before we move on to the next section, there is a point that needs to be addressed. During the consultation, several preoccupations were made explicit by the GP that had some bearing on what courses of action were followed. These are considerations that were taken into account by the GP when deciding which tests should be conducted, and that were not directly related to the chest pain that was being enacted in the consultation:

GP: We send you off to run on a treadmill for a while, wired up to an ECG and do a stress test, which is a cheap and easy test to do and which has a pretty good pick up rate...

And further on:

GP: You don't have any health insurance that covers specialist stuff?

Simon: Yeab I've got health insurance. I think it covers specialist stuff. 
GP: Do you want to check and get back to me? If its one of those policies that just covers surgery it may not cover specialist procedures. But if it does cover specialist procedures then we can whip you up to the clinic and get it (the treadmill stress test) done at your convenience.

Decisions about what action to take are not based solely on the form of the chest pain. Here we can see that the GP reveals other considerations that were taken into account when deciding upon the treadmill stress tests as a further course of action, notably: the cost of the test ("cheap"), and the efficacy of the test ("it has a pretty good pick up rate"). Financing the test is also revealed to be a factor considered by the GP. Whether Simon has adequate private health insurance determines if he will be "whipped-up" to the clinic at his convenience, or alternatively, shunted into the public system.

Latour and Woolgar have noted that scientific practices are often laden with such preoccupations, which consequently influence assembling practices within the laboratory and the resulting construction of facts (1986: 154-159) In our case, via the GP, factors such as cost and finances, and test efficacy, are brought to bear on the assembling of elements within medical practices. These preoccupations cannot, therefore, be divorced from the enactment of entities: they influence decisions about what practices are to be conducted, and thus what elements are to be brought into accounts. They are, in this sense, actors that come to have an affect via the activities of the GP and medical ontology, therefore, is the product of juggling these various considerations.

In this section we have followed the interactive enactment of chest pain as an intelligible entity. We have seen how the translation of this entity is ongoing within the consultation, as some explanatory elements are foregrounded and others fade, and we have seen how, along with preoccupations introduced by the GP, this entity has become the basis for further action. This entity then acquires a degree of solidity and mobility by being inscribed in a written record that can traverse both spatial and temporal distances. A great deal of the action within this consultation has taken place via verbal communication. Elements have been assembled, associations have been made and entities have been made intelligible largely through the verbal interaction between Simon and the GP. In the next section, we will be focusing on material interaction: the treadmill stress test. This is largely coordinated by verbal interaction, but as we will see, the production of intelligibility is brought about via material associations. This will 
provide us with a glimpse at another means by which ontology is constructed in medicine.

\section{Section 2: Enacting the Heart}

The treadmill stress test is conducted at a specialist clinic several weeks after the GP consultation. As we have seen, although the GP doubts that Simon's chest pain is caused by heart troubles, he does state that Simon's history of smoking, and his family history of heart problems, presents enough risk to warrant further testing, and the treadmill stress test is "cheap and easy", with a "pretty good pick-up rate" for heart troubles. Before the actual test begins, Simon has a consultation with the cardiologist responsible for conducting the procedure. It is worth briefly outlining this consultation as several new elements are brought into the explanation of chest pain that are also linked directly to the treadmill stress test.

This interaction takes place in the cardiologist's consultation room, a large room with a bulky desk placed between the cardiologist and the patient. The discussion centres on the nature of Simon's chest pain and the purpose of the treadmill stress test. The cardiologist begins by asking Simon a series of questions about his pain, most of which are similar to the questions put forward by the GP that we have just seen. From Simon's responses, his chest pain is enacted as: not being associated with sweating and nausea; is located in the centre of his chest and does not move to the neck area; is not exercise related, may be related to a family history of heart pains; may be related to a history of smoking, and is not associated with any breathlessness. Some new elements, however, are added to the explanation, notably alcohol and diet. The cardiologist directs the discussion of chest pain towards alcohol consumption and the type of foods Simon usually eats, specifically the quantities of dairy, trim red meat, skinless chicken, fish, and whether olive oil or cream is used as a base for pasta sauces. Consequently chest pain is associated with the consumption, or lack of consumption, of particular foods. Towards the end of the consultation, the cardiologist explains the purpose of the treadmill test and, as we will see, several important elements are brought into the account of chest pain. 
Cardiologist: The heart's a muscle pump and it has three arteries that supplies blood... and what we are trying to do is see if there is any chance you have got a narrowing or a blockage to one of those three arteries that is restricting the blood flow down the artery to the muscle beyond, so that when you stress the heart it doesn't get the blood it needs and you get angina, you get chest tightness. Now in some respects it sounds like it could be angina, but in others, mainly that it is not regularly occurring with exertion, it doesn't sound like angina. So what we are going to do is head down to the treadmill and we will get you wired up and we will check things over and then I'm afraid I'm going to crack the whip and we are going to stress the heart and see if you get any chest pains, if we see any ECG changes to indicate there is a problem and we will really go from there depending on what we find... So, shall we adjourn to the treadmill room?

The cardiologist provides an explicit link between the pain, the heart and its arteries, and the treadmill stress test. The heart is explained as something that causes angina when it fails to receive enough blood due to narrowing of the arteries, and this causes tightness across the chest, or chest pain, and can be identified by the ECG stress test. Here, the heart, blockages, arteries and angina have been brought in as explanatory elements, and a problematic heart has been rendered as something that can be made visible by the testing apparatus. The cardiologist, then, has provided angina as a possible basis for the chest pain while outlining the function of the treadmill stress test.

Simon moves on to the treadmill room. It is here, as we will see, that a largely material assemblage is constructed, where Simon's body becomes entwined in a medical technology aimed at producing an account of the inner spaces of his body. Before we follow this construction process, it is worth reviewing some of the sociological writing on the relationship between the body, technology and medicine, as this will provide some useful points for discussion, as well as providing a context for this approach. 


\section{A Sociology of Techno-bodies}

A great deal of theorising on the relationship between medicine and the body has been motivated by Foucault's archaeology of medical practice, The Birth of the Clinic (1973). Here he contrasts two epistemes of medical thought. Pre- $19^{\text {th }}$ century medicine is characterised by what he calls the "primary spatialisation of disease", where the essence of disease was said to exist in the realm of ideality: disease in its ideal form was foreign to the body, but it would manifest as a bodily lesion; a shadowy, less pure, less truthful replica. Understanding and treating disease thus required making it "transparent to the exercise of the mind" (Foucault 2003: xiv) and the physician's tool was his capacity for rational contemplation, along with a set of elaborate tables and charts of lesion typology. At the end of the $18^{\text {th }}$ century, something of an epistemological revolution occurred. There was a fundamental change, Foucault argues, in the relationship between the visible (the bodily lesion) and the invisible (the cause of the lesion). Bodily lesions were framed as the signs of processes within the body, processes which were the disease itself. With this secondary spatialisation of medicine, understanding disease requires peering into the fleshy compartments of the body, noting its forms, colours, textures, and searching for the most finite, most minute, irreducible source of the ailment: this is the potentially visible essence of the disease (Foucault 2003: 9-13). Disease, then, became embodied, and the eye of the physician became the "depository and source of clarity, it had the power to bring truth to light" (Foucault 2003: xiv) The eye, the physician's unprejudiced gaze, became the means of producing intelligible relationships between bodies, body parts, cells and germs.

Foucault argues that this new episteme was part of a wider movement in western metaphysics towards producing individuals-as-subjects. The individual emerged, not simply as a theological or aesthetic concern, but as the focus of various institutional, practices; modes of inquiry into an individual that labours, an individual that speaks, and an individual that is a product of natural history or biology (Rabinow 1991: 8-9). In medicine, the reorganisation of knowledge brought about by the medical gaze led to the emergence of an individual who, as the source of disease, acquired the status of an object. The body became a bounded assortment of interacting tissues, functional organs with colours, textures and cell-types; and an understanding of not only disease, but also the processes of life itself, was to be found within this bounded, fleshy, tangible and 
visible mass. Life and death were rendered as biological processes that, with a rational mind and an empirical method, could be explained and potentially controlled.

In more recent times, the ongoing search for the processes of disease has led to what Nikolas Rose refers to as the molecularisation of life (2007: 5). Here, the human genome is envisaged as being the basis for not only many diseases, but more importantly, the most minute, irreducible foundation of life. Particular genes or chromosomal arrangements, for instance, are said to be the cause of ailments that manifest as physical or mental states deemed to be abnormalities. Rose argues that this molecularisation of life may have major repercussions for life in the twenty-first century. As particular diseases are reduced to their genetic basis, the possibility of new forms of subjectivities or relations between groups arises: people are made aware of their particular genetic make-up and their resulting susceptibility to particular diseases, and are encouraged to adjust their day-to-day activities accordingly (Rose 2007: 6). Already we are seeing the rise of support groups based on particular genetic illnesses, which seek to share experiences among members, instruct members on how to manage their affliction, lobby for funding into research as well as promote an awareness of the disease (see Rabinow 1996). The spaces of the body, then, become a source of self-understanding and a basis for self-management practices.

Obviously, these new means of self-identification and group-formation could not have occurred without a pantheon of new technologies that have allowed the innerdepths of the body to be made visible. Advances in medical technology have been encouraged by, and have facilitated, the medical gaze and the imperative to delve into the body. From the beginning of the twentieth century, numerous new instruments have been devised to make the internal, organic spaces of the body visible. X-rays, for instance, produced images of denser organic spaces without the need for invasive exploration, as did ultrasound, mammograms, and more recently, PET and fMRI scans (Rose 2007: 14). At the molecular level, the development of the X-ray crystallography, mass-spectrometry, electrophoresis techniques and electron scanning microscopes provided visible renditions of particles too small to reflect the electromagnetic radiation necessary to be detected by the human eye. Such technologies have enabled the body, and the spaces within the body, to become intelligible and amenable to thought and medical management. 
Yet it is not a case of visualisation technologies simply providing a window into the body, through which the unprejudiced medical gaze can peer upon the inner forms as they naturally reside. As Bernike Pasveer has shown in her history of the development of X-ray imaging in medicine (1989), a great deal of ongoing work and manipulation goes into producing an arrangement that generates intelligible information about the body. When nascent radiography was first applied to the body at the very end of the $19^{\text {th }}$ century, no meaningful images could be produced. At the time, there was no readily available medical knowledge which could be used to assess these first radiographs (Pasveer 1989: 363). Because of this, it was not known what a meaningful image would actually look like, and consequently it was impossible to make any distinction between images of spaces within the body and intrusive, visual noise. In order to generate some idea about how radiology could be used and how the streaks and shadows of the radiogram could be interpreted, images were compared to autopsied cadavers and other diagnostic information, and experiments were carried out on the various shadows cast by parts of the body. All this took place as radiography became a specialised profession, leading to a greater homogeneity of instruments, methods and therefore the types of images produced. Pasveer's example illustrates the large amount of work necessary to produce intelligible images of the body. The images alone were not enough to represent the world. A reservoir of knowledge was needed concerning the spaces of the body and the way these spaces interact with electromagnetic radiation, which could then be used to develop and modify the radiograph equipment until it produced the type of images that were expected. Only after years of autopsies, experiments and adjustments, and the standardisation of techniques brought about by professionalisation, could X-ray imaging be equated with the objective, unprejudiced medical gaze, and the internal spaces of the body as rendered by radiography could be equated with a reality.

Donna Haraway makes this point in Situated Knowledges (1991). She talks of the instruments of visualisation in our current technology-laden world, where everything from minute particles, such as proteins and DNA, to huge but distant cosmic phenomena, are reduced to images that are visible to the naked eye (1991: 188-189). Such particles and phenomena are not, in fact, naturally visible to the naked eye: they are either too small to reflect electromagnetic radiation, or, in the case of very large, distant objects, the reflected radiation is too minute to be detected. The production of intelligible images thus requires a great deal of work: particles are bombarded with other particles, reflections are magnified and converted using complex algorithms, and colours 
are artificially enhanced. The consequence is a collection of pictures of just about everything. These come to stand on their own as representations of reality as the instruments and work that went into their production are elided, ignored and bracketedoff from discussion. Haraway argues that we are left with what appears to be a God's eye view, or a detached, objective representation of entities, giving the impression of a great, singular, visual unity to a world that is rendered as transcending the very agents that constructed it (1991: 189). This is particularly the case with images and knowledge of the internal spaces of the body. DNA, proteins, cells, organs and tissues are rendered as elements in a transcendental and indubitable, natural order of things.

But if we pay attention to the great deal of work that goes in to producing such intelligibility, Haraway argues, we recognise that there is no such thing as passive vision and there are no unmediated accounts. All perception is actively engaging in specific ways of seeing immense variation. To put this in the terms we have been using earlier, all knowledge production requires selecting some elements (those deemed to be significant), while ignoring or culling many other potential elements. This is what technologies, particularly visualisation technologies such as radiography do: they ignore some elements, transform others, and produce seemingly stable accounts or representations of reality. How they go about registering and transforming elements while culling many others is the result of years of trial and error, modification and standardisation, all involving a range of actors juggling viewpoints, interests and beliefs. By recognising this and foregrounding technology and practices, Haraway argues that the knowledge that is produced as a result will lose its status as the single true reflection of reality. Other perception systems and means of creating knowledge of the body will be acknowledged, as will the partial, never-finished, "non-isomorphic" nature of identity and subjectivity that arises from such knowledge.

Thus, the re-spatialisation of disease and life within the spaces of the body described by Foucault has brought about a body-as-object. Numerous technologies have been developed to delve into the spaces of the body, and as Rose has noted, this has led to the molecularisation of life and new means of self-understanding and selfmanagement. Medicine and biomedicine have encouraged the production of new technologies aimed at making the internal spaces of the body visible, and as a consequence of this, the body-as-object, the fleshy body that has within it the truths of life and death, has become entwined in a plethora of technologies. The body in medicine 
is swabbed, jabbed, probed, injected, sliced, stitched, magnified, tapped, bombarded with waves of radiation, exercised and so on, by carefully arranged assortments of instruments, in an attempt to make the spaces within the body intelligible. Pasveer and Haraway have illustrated that this knowledge does not simply represent a partial, "God's eye" view. It is, rather, the consequence of practices that place technologies into an intimate association with bodies and body parts, practices that are often elided or ignored giving the impression that such bodily-entities exist as part of an a priori, singular reality that has merely been made visible.

Accordingly, and not unsurprisingly from the ANT perspective, how we make sense of the body is an effect of the assemblage in which it is embedded. Indeed, to even conceive of the body as being something discrete, with particular qualities, capacities and boundaries, is the product of assembling and disassembling practices. Latour uses the example of the training of "noses" in the perfume industry to illustrate this point (2004). Individuals are taught to recognise particular aromas through the use of an odour kit containing a series of fragrances. Some are sharply distinct and provide the individual with the ability to register major contrasts. Over time and with some training, more subtle differences between fragrances can subsequently be recognised. Someone who once lacked the ability to recognise and discern smells thus acquires the ability to register a range of new aromatic elements: they now inhabit a "richly differentiated odoriferous world" and acquire a sensitive, much more effect-uated nose (Latour 2004: 206-207). For the nose to become a sensitive apparatus, something that could be affected by these odours, it had to assemble with the kit, and the elements of the training session. It was the product of an assemblage, as was the new world that it created. The kit is coextensive with the body; without it, the nose would have remained insensitive, dumb. As Latour puts it, to be made aware of our body, to feel it and to talk about it, we need associate with other entities, made to be moved, affected, and thus become sensitive. Our body, then, is an interface that becomes more and more describable as it learns to be affected by more and more elements: "acquiring a body is thus a progressive enterprise that produces at once a sensory medium and a sensitive world" (Latour 2004: 207).

With these points in mind, it is perhaps more expedient to refer to techno-bodies. A body on its own is insensitive, it is not made to move and it is not affected. We might say that it is dead. A body that is aware, that is made to move by a rich, stimulating 
environment, is one that is, and has been, well associated with other elements, somatic and non-somatic. To be embodied, to experience bodily sensations and register the environment, is to have a hybrid-body: a body intimately coexisting with its surroundings. In medicine, which has become saturated with technologies, we might call this a techno-body. Furthermore, if assembling with non-somatic entities is necessary for the body to become sensitive to its environment, and if such assemblages are necessary for making the body and its parts intelligible as an entity, then we should refrain from making any a priori distinctions between a body and its non-organic surroundings.

This proscription underlies our method in this section. We will be following how it is that an account of Simon's heart is produced during the treadmill stress test, noting which actors are involved in the production of this account, and which elements are brought into the explanation. Importantly, as has been made clear throughout this project, these actors and elements may take any form: they may be human or nonhuman, material or discursive. Indeed, we will see that as Simon undergoes the treadmill stress test, the boundary between his body and the ECG instrumentation breaks down. We have, then, a techno-body which produces an account of the heart. From a wider sociological perspective, by foregrounding the practices used to produce this account, we will be witnessing how it is that the medical gaze, or "God's eye" operates; the techniques through which the internal spaces of the body are made visible, and how it is that these spaces become amenable to medical management. To put this differently, we will be uncovering how the body becomes intelligible through its interaction with medical technologies and how, as a result, the spaces of the body can become a basis for self-understanding and therefore self-management.

\section{The Treadmill Stress Test}

\section{1 - Aligning the elements.}

The testing room contains a narrow bed for the patient, the ECG equipment and instrumentation for measuring blood pressure, and placed in the centre of the room, taking up a great deal of space, is a large, bulky treadmill. Simon sits on the bed while being prepared for the test by a medical technician. 
Simon has been instructed to remove his shirt and the technician begins to swab parts of his upper torso with alcohol. This, she states, cleans the skin to insure the electrodes make "good contact". She attaches, one-by-one, ten electrodes to Simon's torso, each at specific locations: one is placed either side of the centre of the chest, and five more are attached towards his left side, arranged in a curve towards the armpit; two are attached to the front side of each shoulder, another just above the belly-button, and the remaining electrode is placed to the left of the abdomen.

Technician: Electrodes are now attached. So, you have been experiencing some chest discomfort. Shortness of breath?

Simon: None of that, no, just feeling tightness in the chest area. Discomfort, really.

Technician: So, once we have hooked you up to the computer, we will give the specialist a call. He will put the blood pressure cuff on you and take your blood pressure and have a chat to you and get the test underway. The treadmill starts off quite slow on a slight incline and it increases every three minutes. If we find that your heart rate isn't increasing fast enough we'll just accelerate the protocol and go a little bit faster. Have you walked on a treadmill before?

Simon: $\quad$ No

Technician: $\quad$ There are a few things to remember when you are walking on a treadmill. One is to keep your toes at the front when you're walking. Now, could I ask you to just stand there on the carpet for me? I'm just going to pop this belt on... and that's not too tight?

Simon: No, that's fine. 
The belt that has been put around Simon's waist contains a series of wires which the technician attaches to the electrodes.

Technician: So if you would like to come and stand on the treadmill for me. So as I was saying before, when you walk on the treadmill just try and stay nice and close to the front. Just try and only use this bar here for balance. Try not to grip too tightly. The main thing is to feel like you are walking on a normal flat surface.

Simon: Okay, fine.

Technician: So I will just enter your details bere [on the computer].

At this stage, Simon is standing on the treadmill with wires attached to the electrodes on his torso which, via his belt, are attached to the ECG device. The Technician calls the cardiologist, informing him that the test is ready to begin. The cardiologist enters the test room, places the blood pressure cuff around Simon's arm, and takes a measurement.

Technician: Excellent. So I'm just going to start the treadmill there Simon. Nice long steps.

Cardiologist: Just longer steps and slower steps. There, that's good. And maybe move a bit closer to the front. Nice and slow and steady.

After a minute the speed of the treadmill is increased and Simon's strides become quicker. 
Cardiologist: We're going to go a little bit faster. Slightly longer steps there, just feet forward at the front. Slower, longer steps. Just relax, belp the ECG tracing. So bow are you feeling, alright?

Simon: Alright.

After another minute, the treadmill speed is increased again. The cardiologist is standing next to the treadmill and takes another measurement of Simon's blood pressure, while the technician appears to be making notes on the ECG printout towards the side of the testing room. Another two minutes pass and the treadmill speed is increased for a third time. By this stage, Simon is noticeably breathless and producing a sweat.

Cardiologist: So are you right for another, about probably forty five seconds?

Simon: $\quad$ Yep.

Cardiologist: Just let me know if you feel you can't cope. Just come a little bit closer to the front. About fifteen seconds and you will be able to have a seat... Ten seconds to go...

Okay. Just stay there.

At this point, the treadmill is stopped and the cardiologist places a chair on the treadmill for Simon to sit on.

Cardiologist: Okay, how you doing? Chest pain or chest tightness?

Simon: Nothing. 
We can see from this that the setting-up and conducting of the test is a matter of physically aligning various objects. Firstly, the electrodes are attached at very particular locations on Simon's body. These locations are the standardised electrode placement points, as prescribed by cardiology and medical manuals, and are said to be ideal for detecting electrical activity in particular parts of the heart. The electrodes, then, are being aligned with objects within the body: the electrical impulses that trigger heart function. Secondly, Simon aligns his body with the treadmill. This interaction is closely monitored and coached by the technician and cardiologist. Simon is instructed to feel like he is "walking on a flat surface", keeping his strides long and slow, with toes reaching towards the front of the treadmill. The pace of his strides is controlled by the speed of the treadmill and the duration of the test is determined by the cardiologist and technician. The co-ordination of Simon's body, and thus how it aligns with the treadmill, is therefore regulated. Thirdly, the various components of the ECG device are aligned. The wires are attached to the electrodes, and these are subsequently connected to the print-out machine which records the ECG data.

The alignment of these objects during the test, or elements as we will now call them, brings about the material assemblage that enacts the heart. The careful placement of these elements regulates which other elements will be included in the assemblage; it insures that no unwanted, unpredictable, or unaccounted objects have an effect on the assemblage. For example, the technician informs Simon that the alcohol swab will "clean the skin" and insure the electrodes "make good contact". Cleaning the skin is a matter of removing any particles that might interfere with the registering of electrical impulses by the electrodes. Particles may interfere with the capacity of the ECG equipment to detect heart function, producing an incomprehensible or misleading result. Carefully placing and aligning the elements, then, is a protection against noise; it is an attempt to silence as much complexity as possible and allow only a few elements to act and thus produce an intelligible signal. The treadmill stress test, as a regulated alignment of elements, is a means of insuring that certain other elements within the body, the electrical impulses of the heart, can be deciphered, while many other elements are left silent through their deliberate or unintentional but necessary exclusion.

It should be noted that many of the elements that compose this assemblage were carefully and strictly aligned prior to the test. The machinery that make-up the various 
instruments of the ECG is an example of this. The technical components that makes up this machinery, particularly the print-out device which contains a series of oscillating needles, have been carefully aligned in their construction which has been fixed as physically-bounded apparatus. This insures the technical components operate as the designer or engineer intended and reduces the possibility of unwanted, foreign actors. Through its construction, it insures that it interacts with surrounding elements, such as the electrodes and the electrical impulses of the heart, in a predictable fashion, provided it is used correctly. In this sense, we can say that the device as a whole operates as an important actor in this assemblage: without it and the designer's knowledge and beliefs that it incorporates, the electrical impulses of the heart would fail to produce any intelligible signal.

Obviously the functioning of this actor is dependent on the two other principal actors of the assemblage: the technician and the cardiologist. As we have seen above, both play a pivotal role in insuring that all the elements of the test, particularly Simon's body, are aligned correctly. The technician is responsible for cleaning the skin and attaching the electrodes, and both, as we have seen, coach Simon on how to interact with the treadmill. As actors, both the technician and the cardiologist bring their training and previous experiences to bear on the assembling of elements.

\section{2 - Transforming matter}

The careful alignment of elements, therefore, regulates which other elements will be included in the assemblage. While unwanted elements and the noise they tend to produce are restricted from the interaction, others are encouraged to participate. We have already seen how the correct placement of the electrodes insures the electrical impulses controlling heart function can be deciphered, but it is worth noting a few more, as these constitute a series of transformations that are necessary for the enactment of the heart.

As the technician and cardiologist verbally instruct Simon to lengthen his steps, and as his paces speed-up in-tune with the treadmill, Simon's exercising muscles are induced to increase metabolic activity in order to produce the necessary energy required 
for the movement. This requires plenty of oxygen, provided by blood which must be circulated by the heart. As the rate of activity increases, so must heart activity to insure sufficient oxygenated blood is supplied to Simon's muscles. This activity is regulated by electrical impulses which travel from the sinoatrial node to the various parts of the heart. This electrical activity induces a corresponding agitation of electrons on the electrodes attached to Simon's chest, initiating a movement of electrons throughout the wires to the print-out device. Electron movement causes a series of needles to oscillate, which leave an ink mark on a slowly scrolling, roll of standardized ECG graph paper.

Here we have a series of elements which are induced to participate in the assemblage; they too become elements that are aligned. Simon's muscles fibres, his circulating and oxygenated blood, his beating heart, the metal electrons in the electrodes and wiring, and the needles of the print-out device, are made to act, inter-act, to have an affect. We could say that particular capacities of interaction of each of these elements are being realised and utilized through their association in order to enact the heart. As the inter-action takes place during the test, there is a series of transformations going on as matter is being transformed from one state to another. The verbal instructions of the technician and cardiologist, and the movement of the treadmill, are converted into muscular movement by Simon. The events in Simon's body are transformed into electron movement in the ECG device, which subsequently transforms this into an ink pattern on graph paper. Traditional physical boundaries of the body are traversed as somatic elements within the body respond to some extra-somatic elements, which, in turn, transform other extra-somatic elements. So, in order to generate meaningful scribbles on the ECG graph paper, an assemblage is constructed that is a mixture of coordinated, interacting somatic and non-somatic elements. We have here, then, a hybrid assemblage of the organic and the non-organic.

\section{3 - Speaking for the Heart}

The product of this assemblage, aside from Simon's breathlessness and sweat, is the ink scribbles on the graph paper. Events taking place inside Simon's body have been inscribed on a scroll of paper that can then be read as an indicator of the ability of the heart to function correctly under stress. By aligning the elements carefully, bringing 
desired elements into play and preventing unwanted actors from appearing, the heart is being enacted. The heart has been enacted by a largely material assemblage, which as we have just seen, includes a range of elements: our principal actors, the cardiologist and the technician; the machinery of the ECG device; the treadmill; and the various elements within Simon's body which have been induced to participate.

This assemblage constitutes what Latour refers to as an inscription device. These are configurations of elements that transform a material substance (in this case the electrical impulses of the heart) into a figure or diagram (the ink marks on the graph paper) which is directly usable (Latour 1986: 51). The diagram or figure produced is regarded as having a direct relationship to properties of the matter it was transformed from. At the end of the test, while Simon sits down on the chair that has been provided for him, the cardiologist is able to use this ink inscription to make a judgement about the health of the heart.

Cardiologist: Okay, well, that all looks very good. You did a really good stress test, we got you over a hundred percent maximum heart rate so it means we really stressed the heart... there's been nothing on the ECG, so that's a normal stress test.

Simon: Okay.

Cardiologist: So therefore I don't think the chest tightness and things you're getting is angina and from that point of view I don't think we need to worry about doing the other types of tests or anything... Basically the treadmill test has gone fine.

Here a particular diagnosis, angina, is rejected. This constitutes a translation, which is made on the premise that the inscription has a direct, representative relationship with the properties of the heart. Latour has noted that within the scientific community, once the inscription has been produced and the parts of the inner body have been made visible, 
the very implements that went into its construction are often ignored and absent from conversation (Latour 1986: 51). The highly contingent nature of the inscription or image is overlooked, and it therefore comes in to stand on its own as a reflection of reality. A fact is constructed, but the apparatuses of construction are invisible: that fact stands on its own. Certainly at this stage the cardiologist is treating the inscription as a trustworthy representation of the heart's function, but it is not yet clear whether the assemblage that produced it will be bracketed-off from conversation. We will come back to this point in the next section.

It is worth noting that via the inscription device, the cardiologist has situated himself as the spokes-agent for the heart. Although he appears to be tentative about his rejection of angina as a cause, indicated by phrases such as "I don't think the tightness and things you're getting are angina", he is nonetheless claiming to represent the properties of the heart. The heart has been enacted, or translated as having normal function, and it is the cardiologist who makes this final proclamation. And, via the assemblage, the heart has been imbued with qualities that allow the cardiologist to make decisions about what further steps need to be taken. The heart, then, has become the basis for further action. In this case, the action taken by the cardiologist is to state that: “I don't think we need to worry about doing the other types of tests or anything".

Simon's role as an actor is much more limited in this assemblage. In the GP consultation, we saw that he was a major actor in bringing elements into the enactment of chest pain: it was through the interaction between him and the GP that his chest pain acquired the form that it did. In the assemblage above, we have seen that his body and elements within his body are necessary for the enactment of his heart to take place. He must coordinate his body as instructed by the technician and cardiologist, but any compliant body would have been sufficient. In a sense, Simon, as a decision-making, feeling, emotional individual is absent from this assemblage. He is physically present, but none of these so called subjective capacities for interaction are realised in the interaction. The way that his body is positioned and coordinated is the consequence of his compliance to the instructions of the principal actors, the technician and the cardiologist, and consequently, Simon's role as an actor is almost non-existent. His body and body parts are involved in the aligning of elements, but Simon, as a potentially subjective, emotional being, plays very little role in the enactment of his heart. 
We have seen how it is that an assemblage is constructed, and how this assemblage enacts the heart. The technician and cardiologist carefully align a series of elements, including Simon's body, the treadmill, and the components of the ECG device (which, through its construction and design, are preset to interact in a particular way). This careful alignment insures that some elements within the body are made to interact, to have an effect and thus speak, while the many unwanted, potentially noisy actors are avoided. Through the interaction of these coordinated elements, a series of matter transformations take place which result in the production of an inscription. This inscription is presumed by the cardiologist to represent the functioning of Simon's heart, which, as a consequence, is translated as most likely being healthy. The assemblage is a hybrid composed of both organic and non-organic elements; it is what we might call a techno-body, almost divorced from subjective capacities of the body's possessor, Simon.

The assemblage can also be seen as a transient machine for producing a sense of order from monadic complexity. While the test takes place and Simon runs on the treadmill as instructed, while his heart responds to electrical impulses from the sinoatrial node and is forced to pump oxygenated blood to his exercising muscles, while electrons within the electrodes respond to these electrical waves, travel along the wires and induce the oscillation of a needle that leaves an ink mark on standardised graph paper, we have the transient, coordinated inter-acting of elements. We have an inscription, an intelligible representation of the heart. This is the fleeting production of order from the otherwise noise-ridden, messy complexity of flesh and blood, wires, swabs, papers and the idiosyncrasy of humans. So far on our foray through the healthcare system with Simon, we have seen two ordering practices take place. In the GP consultation, we had the enactment of chest pain. This led to series of further actions, one of which was the assemblage, the enactment of the heart, we have just witnessed. Our next task, then, is to follow Simon one further step as he partakes in a treadmill debrief consultation with the cardiologist. This involves, as we will see, a third ordering practice, one that aims to provide a sense of overall coherence to the two enactments we have seen up to this point. 


\section{Section 3: Coordinating Coherence}

In our first location, we had the enactment of chest pain. Through the interaction of the GP and Simon, chest pain became intelligible as a tightness in the chest area, not being associated with nausea and sweats, not radiating the arm or neck, and was associated with a family history of heart problems a history of smoking, and stress and anxiety - a translation consolidated by the GP in Simon's medical notes. In our second location, the treadmill stress test, we have an enactment of heart function. Via the careful construction of an inscription device, the heart was made visible, intelligible, as not causing angina and as free of blockages or narrowings. In two locations, then, we have two different assemblages and two different enactments; two different ordering practices have produced two intelligible entities. Simon, the GP, and the cardiologist could leave it at this. The two enactments could be seen as just that: the contingent products of two, discrete assemblages at two discrete locations: multiple worlds producing their own, distinct objects of the body. If such a viewpoint was taken, if such objects could be seen as simply occupying separate worlds characterised by different ordering practices, then Simon's medical foray could end here. He, along with the GP and cardiologist, could settle on the knowledge that in one location Simon has chest pain with particular characteristics, and in another, Simon's heart function has its own particular set of characteristics.

This approach, however, is not taken by the cardiologist. As we have already seen, the treadmill test was predicated on the presupposition that Simon's chest pain and heart function could be linked:

GP: $\quad$ Obviously, the pain, what you worry about and what we worry about it whether it is coming from the beart... I think we need to look at... send[ing] you off to run on a treadmill test... It has a pretty good rate for picking up a heart that's not getting as much oxygen as it wants.

We have also seen the cardiologist make the same link, adding angina into the explanation: 
Cardiologist: : The heart's a muscle pump and it has three arteries that supply blood to that muscle, and what we are trying to do is see if there is any chance you bave a narrowing or a blockage to one of those three arteries that is restricting the blood flow down the artery to the muscle beyond, so that when you stress the heart it doesn't get the blood it needs and you get angina, you get chest tightness... So what we are going to do is head down to the ... see if you get any chest pains, if we see any in your ECG changes to indicate there is a problem.

The GP and cardiologist both frame chest pain as something that is often linked to the heart. Chest pain can be angina, and it is a symptom of blockages of the heart arteries (the cause). This symptom-cause rendering of chest pain and heart function discloses a belief in a singular, coherent reality, where chest pain and heart function, regardless of where and how they may be enacted, can occupy the same, coherent body. In this section, we will see how this belief is further manifested in various actions, and how it influences the final diagnosis, or translation, of Simon's heart and chest pain. This final translation takes place back in the cardiologist's consultation room, just after the conclusion of the treadmill stress test. The cardiologist has settled into his chair behind his desk, and Simon occupies one of the two patient's chairs directly in front. Again, before we begin with this post-treadmill debrief, I will provide some theoretical background.

\section{A Sociology of Reality}

Within the last hundred years or so there has been a significant division between thinkers who subscribe to the belief of a universal, coherent reality, and those who dismiss such ideas as naïve and totalising. A great deal of the debate between these two groups has been stimulated by those studying scientific practice and method. Here I will briefly discuss some of the arguments of those involved in this debate, as this will provide us with context to the approach that we will adopt for this section.

The notion that there is an external, singular reality, which, with good scientific practice, can be rendered intelligible, was challenged with some force by Thomas Kuhn's The Structure of Scientific Revolutions (1962/1996). Kuhn disputed the idea that science was a unified movement involving the linear accumulation of facts. He argued that scientific 
activity took place within particular paradigms which provide a conceptual framework influencing the sort of experiments that would be undertaken and how the results would be perceived (Kuhn 1996: 24). As anomalies and inconsistencies accumulate in these periods of normal science, scientific revolutions occur bringing on a new paradigm (Kuhn 1996: 53-65). Rival and successive paradigms are often incommensurable, and the conceptual framework of one paradigm cannot be understood in another (Kuhn 1996: 112). Although there has been some debate over whether Kuhn is arguing for a relativist account (Kuhn 1977), he does suggest that it is not useful to assume the existence of a singular, true account of nature. As paradigms change, so do worldviews (Kuhn 1996: 111). Science may increase in complexity as revolutions occur, but this does not necessarily constitute a progression towards one truth. Kuhn, therefore, points towards a pluralism of knowledges and worlds.

Ian Hacking has also commented on this apparent incommensurability in science practice, although he takes a more materialist stance. The instruments in one paradigm may differ markedly from those of another (Hacking 1992: 56): the form of the experiments that can be conducted and thus the type of results generated are often significantly different between paradigms, thus producing divergent areas of knowledge. Disunity in science is because phenomena are produced by divergent techniques and instrumentation, and corresponding theories are produced that are true to these particular phenomena (Hacking 1992: 57-58). There is no single truth, or no single reality that is being uncovered. Practices, instruments and theories construct various knowledges. As Mol states, Hacking is suggesting that a "plethora of techniques makes for a multiplication of reality" (Mol 2002: 75).

Hacking does not, however, investigate how such realities are negotiated; whether differing worldviews are able to coexist, or whether such diversity is ignored to sustain a belief in a singular, coherent reality. Mol examines such negotiations in The Body Multiple (2002). In the hospital, different practices enacted multiple atherosclerosies. In some cases, these enactments could coexist without the need for the prioritising of one over another, particularly when these enactments were taking place in discrete locations. But, as Mol puts it, "the body multiple hangs together" (2002: 55): different locations were linked, often by the circulation of a patient's medical file, which would coordinate different enactments into a representation of a single, coherent patient. If contradictions occurred between enactments, such as a patient's experience of pain and 
the clinical diagnosis, one would have to be discarded, by pointing to the fallibility of either the patient's "subjective feelings", or the clinical equipment (Mol 2002: 62). Coherence is also achieved by employing stories about how particular enactments hang together, aetiological stories about how the cellular events, for instance, cause the various pains experienced by patients (Mol 2002: 60). As Law puts it: "alongside the practices of multiplicity, there are endless practices insisting on, presupposing, and producing singularity" (2004: 65).

Coherence, then, is an achievement. There are different realities produced by different practices, but these can be, and often are in a hospital, amalgamated to produce a singular, coherent order of things. The position of Hacking and Mol that we are adopting here sees knowledge as being unique to the situation in which it was produced. Coherence is possible. But to create a situation where a singular viewpoint is achieved, would require domination: it would necessitate the spreading and circulating of the various practices that insist on, presuppose and produce singularity. Again, we are not interested in presupposing the existence of a particular type of world, or a fundamental incompatibility between distinct worlds produced by distinct knowledges. Following Mol, we are interested in how such situations are produced; how it is that actors create multiple worlds, and how it is that multiplicity may be coordinated to produce a sense of coherence and singularity. In this section, then, our task is to again follow the actors. We will observe the cardiologist and Simon as a final diagnosis is achieved. This enactment involves a series of ordering practices that coordinate the two previous enactments of chest pain and the heart, into a single, coherent body.

\section{The Post-treadmill debrief}

\section{1 - Symptom-cause coherence}

Before we begin following the debrief, it is necessary here to highlight the role of medical notes in linking enactments and providing a sense of coherence in Simon's case. A copy of Simon's medical notes, which, as we saw in the consultation, were written by the GP, was sent to the cardiologist along with a brief referral letter. Simon's name, age and ethnicity are stated at the beginning of the notes, and below, along with the details of his 
chest pain, are the results of the various tests ordered by the GP. The cardiologist was therefore aware of Simon and the details of his chest pain prior to the treadmill test. At the end of the test, the ECG results were added to the notes, which were to be returned to the GP. The notes, then, are effectively linking the various locations where enactments took place, coordinating and adding the knowledge produced in these locations into a representation of a single patient. In other words, Simon's medical notes pull-together discrete assembling practices by combining the various entities they enact, under the name of a specific individual. These medical notes are not the only coordinating practices we see, however. Throughout the debrief, the cardiologist employs other means of creating a sense of coherence and singularity.

The debrief begins with the cardiologist restating the purpose of the treadmill stress test. In doing so, he explicitly links the enactment of chest pain and the enactment of the heart together.

Cardiologist: $\quad$ The most important thing we've done this afternoon is looked at the heart and tried to decide whether you presently have any narrowings and blockages in those arteries to explain the chest tightness.

Again, chest tightness is framed as a symptom, and narrowings of the arteries are framed as a possible cause. Both enactments are seen as representing linked objects within the one body, Simon's body. The cardiologist then goes on to restate the findings of the treadmill test:

Cardiologist: You've done an excellent treadmill test, taken you to the maximum predicted heart rate, no problems at all. No symptoms, notbing on ECG, everything's good.

There is a problem here, however. If Simon's chest pain is a symptom, then there must be a cause. Yet the treadmill stress test failed to find a cause. The two enactments are 
thus potentially contradictory, as one suggests the presence of heart problems and the other indicates the absence of heart problems. This would not necessarily be problematic if the two enactments were seen as the contingent products of two, discrete practices, producing different worlds. But, by making the symptom-cause link, the cardiologist is required to explain the potential contradictions. Two tactics are used by the cardiologist to do this. The first is to suggest other causes:

Cardiologist: $\quad$ You might find that that's... muscular skeletal sort of tension, chest wall discomfort that we can all get if we worry or get stressed about something. We can sort of overbreathe a little bit and that can bring on the tension and chest discomfort in the chest wall, so I suppose in a way I'm putting it down to that maybe being a cause for your chest pain.

Here, the cardiologist brings in "muscular skeletal tension", "chest wall", "stress", and "worry" as explanations for Simon's chest pain: stress and anxiety are therefore being put forward as a cause. This is not surprising, since this was stated as the most likely explanation of Simon's chest pain during the GP consultation, and the cardiologist's findings would indicate that the GP was correct in stating that it "is not heart related. I suspect its coming from the chest wall". The cardiologist also speculates on another possible cause, the stomach:

Cardiologist: $\quad$ Alternatively, the other option in terms of chest pain, can be coming from your stomach. And so if your GP's concerned about that, sometimes have a look in your stomach to see whether there is any reason there why you get chest pain.

By putting forward both the stomach and stress as possible causes for Simon's chest pain, the cardiologist is able to provide an explanation for both enactments while maintaining the idea of a coherent, singular body. The enactment of Simon's chest pain can be explained as a symptom of processes that would not have been detected in the 
treadmill test. Simon, therefore, has chest pain as enacted in the GP consultation, he also has a healthy heart, free of blockages and narrowings, as enacted in the treadmill test, and he has either a troublesome stomach or tightness of the chest wall caused by stress. In this situation, both enactments are seen as producing reliable information about one, coherent, singular body.

\section{2 - Destabilising enactments}

At this point it could seem like we have a final diagnosis, or translation, for Simon's chest pain. The cardiologist appears to have proven that it is not heart related, and along with the GP, has stated that stress and anxiety are the most likely cause. The possible contradiction between the two enactments has been avoided. But the cardiologist makes another suggestion to Simon. This is the second tactic he uses to explain the possible contradiction.

\section{Cardiologist: A precaution: the treadmill test is just the basic screening test and there is a chance its wrong.}

In this situation, the inconsistency between Simon's chest pain and heart is explained as being the result of a possible inaccuracy. The treadmill test, a "basic screening test", might be "wrong", suggesting that it may produce an inaccurate or false representation of the heart, and the cardiologist, therefore, is suggesting that Simon's heart may have blockages or narrowings that are causing his chest pain.

What is interesting here is that the means of doubting the reliability of the enactment of the heart is to highlight the contingent nature of its production. The presence of Simon's chest pain, for example, has not been doubted by the cardiologist. It has been dealt with and talked-about as though it is a fact, not just the product of the assembling practices within the GP consultation. The "healthy heart, free of blockages", however, has been undermined by linking it to one of the conditions of its production (the treadmill test), and by pointing to the fallibility of these conditions ("there is a chance its wrong"). As the product of a fallible test, the representation produced by the 
inscription device, therefore, does not necessarily represent any facts about the heart. As Mol has noted, by unbracketing the practicalities of measurements, the findings of such measurements can be discarded (2002: 64). This second tactic of maintaining coherence, therefore, involves undermining the accurateness of an image or representation by exposing the usually invisible conditions, or parts of the assemblage, responsible for its production. It is no longer a "fact" that stands on its own; but rather the product of various fallible apparatuses.

By adhering to the symptom-cause link, the belief that chest pain is a symptom of events within the same body, the cardiologist has had to employ two tactics As we have seen, he has to either postulate another (quite likely) cause, or suggest that one of the enactments is mistaken. The effect of employing these two tactics is to reproduce the integrity of the singular, coherent body; a body where a troublesome stomach or anxiety cause chest pain, or a body where heart blockages and narrowings cause chest pain.

By employing the second tactic, the cardiologist is indicating that the integrity of the coherent body is more important than maintaining confidence in the ability of particular tests to produce accurate results. If contradictions occur, it seems enactments will be sacrificed in favour of maintaining the singular body. This tactic, however, has repercussions for the concluding translation of Simon's chest pain.

\section{3 - Surveillance and self management}

In section 1, we saw that Simon's chest pain was translated as being associated with stress and anxiety, a family history of heart disease and smoking, and possibly the presence of "unhappy heart cells", to quote the GP. This was consolidated within the GP's medical notes, a copy of which was sent to the cardiologist. We have also seen, in this section, that by employing the first tactic to avoid contradiction, the cardiologist confirmed the association between chest pain and anxiety. If it were not for the second tactic, the cardiologist may well have enacted chest pain as a symptom of anxiety. 
In utilising tactic 2, however, the unlikely but nonetheless risky association between chest pain and the heart, which was first made in the GP consultation, persists, and it is still possible that Simon's chest pain is a symptom of heart problems. Because of this risk, the cardiologist issues the following instructions:

Cardiologist: $\quad \ldots$ and there is a chance [the treadmill test] is wrong, and so if you find your symptoms changed, in particular if you start getting, as you're walking up those steps at home, if you start finding you do get chest tightness or chest pain in that situation, then come back and see us, because there are other more accurate tests we can do to look at see whether this is a problem.

Simon: Yep, okay.

Here, the cardiologist is asking Simon to take note of any possible changes in his bodily experience of pain as he undertakes certain tasks; specifically, to be aware of any chest tightness occurring as exercise is undertaken. Simon is being instructed, therefore, to be vigilant and engage in self-surveillance of his exercising activities and particular bodily sensations. The cardiologist makes some further suggestions:

Cardiologist: So, just moving onto the preventative side of things. The best thing you did for yourself was to stop smoking, that halves your chance of coming back with a cardiac problem, so we don't have to worry about dwelling on that.

Simon: $\quad$ Yep.

Cardiologist: And, in terms of preventing cardiac disease, the other thing that is important of course is your cholesterol. Your GP has given us that your cholesterol is four point three. 
What we are actually more worried about is your LDL cholesterol, which is the really bad part of the fat, two point five. Considering your HDL, which is the good part of the fat, which, if you like, goes around scavenging that bad fat. Okay, so your HDL is normal and your LDL is satisfactory, so we don't need to start you on any cholesterol therapy.

Firstly, the cardiologist introduces smoking and cholesterol, both its "good" and "bad" components, into a discussion about preventing cardiac problems. Both are framed as elements that Simon must take into account and manage in an attempt to maintain a healthy heart. Smoking must be avoided, and both HDL and LDL must be maintained at various "normal levels".

Cardiologist: $\quad$ Your blood pressure is another risk, that's fine, so I don't need to start you on anything there... A small dose of aspirin reduces your chances of stroke or heart disease so I'm happy with you to carry on with that.

Secondly, "blood pressure" and "aspirin" are introduced as an element requiring some sort of management, and Simon is encouraged to maintain taking a "small dose" of aspirin daily.

Cardiologist: $\quad$ Your diet was good, so yeah, really it comes back in terms of just thinking about your lifestyle and things. Its just a matter of trying to encourage you to do more exercise, you know, maybe park further from work... you know, just go for a walk everyday, forty five minutes. Doesn't matter if its gym, walking, swimming, whatever, cycling.

Simon: What about an exercycle at home?

Cardiologist: Absolutely fine, whatever. 
Thirdly, exercise, specifically forty-five minutes each day, is suggested as a requirement for a lifestyle that decreases the chances of cardiac problems, and walking, gym, swimming, cycling, and parking further from work, are framed as preventative measures.

Cardiologist: $\quad$...forty five minutes a day is good for you. And don't forget the fish either. . Two fish meals a week.

Simon: $\quad$ Yes, I must try and find some new recipes.

Cardiologist: It is good for you.

Simon: $\quad$ Yeah it's just my partner doesn't like fish very much you see, and she does the cooking.

Cardiologist: Get maybe fish when you go out to a restaurant. Just whatever. I think fish would be the only thing I suggest in your diet because it seems like you are doing everything else.

And fourthly, we see that Simon is encouraged to eat fish twice a week: eating fish is framed as a management technique for avoiding cardiac problems.

Because of the risky association between Simon's chest pain and heart disease, the cardiologist is encouraging Simon not only to be vigilant, but also to manage his dayto-day activities so that he can decrease the likelihood of cardiac problems. The cardiologist has, in effect, outlined the criteria necessary for a healthy lifestyle centred on avoiding cardiac problems. He has stated what sort of factors need to be considered; smoking, cholesterol, blood pressure, exercise and diet, and how these are best managed; avoidance, aspirin, daily exercise, and consuming fish. And while it is the cardiologist who stipulates these criteria, it is Simon who is issued with the responsibility for adhering 
to this lifestyle: in addition to monitoring his own bodily sensations, Simon must also insure that he, himself, takes aspirin, exercises forty-five minutes each day, avoids smoking, and eats fish. Simon, then is, being enacted as a self-responsible individual.

In the process of having a series of criteria for a healthy cardiac lifestyle mapped out, Simon is being made conscious of a world of entities of which he may have previously been unaware. The cardiologist has provided a list of elements which Simon must now take into account in his day-to-day activities. He must pay attention to particular things that previously were just part of an undiscernible, un-affecting mess, an ignorable background to his everyday activities. These things have now become actors: things to be aware of, to take note of, and according to which he must regulate his behaviour. Simon, if he has listened to his cardiologist, is now sensitive to chest tightness while exercising, HDL, LDL, fish on a restaurant menu, and parking distances. Such elements have been made visible, or at least reframed, in terms of a healthy cardiac lifestyle which Simon has been instructed to follow. So, as well as being enacted as a selfresponsible individual, Simon has also been placed within a constructed world; a world where cardiac-health influences which elements are to be noticed and which practices should be undertaken. Of course, whether Simon stays attentive to such a world, or quickly recourses to a more familiar, "pre-cardiac" habitual world is another question. And, the two worlds may not be that dissimilar: Simon has no doubt been exposed to the many, widely circulating messages linking heart disease to diet, smoking, and so forth, for most of his adult life. But nonetheless, the interaction with the cardiologist has, at the very least, reasserted the immediacy and relevance of a world where lifestyle is orientated towards cardiac health.

So, in this post-treadmill debrief, we have the enactment of Simon as a self-responsible individual, and the enactment, or reproduction, of a world of cardiac health-relevant practices and elements. What, however, can we say about the enactment of Simon's chest pain? Our principal actor here, the cardiologist, talked about a chest pain that is most likely caused by anxiety, and may possibly be related to stomach troubles. But the diagnosis did not end here. He also talked about a chest pain, the same chest pain, as being the unlikely but nevertheless possible symptom of heart troubles. The treadmill test, he said, was fallible and the risky link between chest pain and the heart could not be discarded. Because of this, Simon was instructed to be alert to any additional symptoms. 
We have, therefore, a chest pain that is most likely a symptom of anxiety, but possibly a symptom of stomach troubles, and possibly a symptom of heart artery blockages and narrowings. The exact nature of the chest pain, then, is indefinite. It is not enacted as a solid, precise, bounded entity: rather, it is open and unclear, potentially hazardous and a source of vigilance and self-management. It is most likely linked to anxiety and therefore associated with a range of psychological elements, but it retains its links to a troublesome heart and thus all the corresponding cardiac elements. Where its associations begin and end is not exactly known, and it has resisted the culling of explanatory elements that would allow a more definite translation. This is the cost of assuming the existence of a single, coherent reality and the consequence of the cardiologist's employment of the two tactics above. The enactment of chest pain and the enactment of the heart, despite the contingent nature of their production, are coordinated, added together, as though they represent linked elements or events in one coherent reality. Chest pain is a symptom, and along with its cause, it occupies a single, coherent body. As a consequence, rather than having two discrete enactments occupying distinct assembling practices, we have one body and one reality, where chest pain has been enacted as a single but indefinite and imprecise entity. Perhaps, as Law suggests, much of the world is enacted in this way (2004: 14). 


\section{3 - Discussion}

In the preceding sections we observed three instances of medicine in action. In each case, adhering to the proscriptions of Actor-Network theory, we witnessed a series of assembling practices. Some elements became associated to create an account or an enactment, while many more elements were elided, ignored, or discarded. Rather than limiting ourselves to following so-called "social" phenomena, we expanded our vision to include a longer list of practices and elements. We also refrained from making any presuppositions about whom or what could be principal actors in constructing such accounts. And rather than insisting upon an underlying singular reality, or a multiplicity of realities, we watched how these were created by various assembling practices. 
In this discussion we will briefly overview what we have seen in each of the three interactions. Firstly, I will relate my findings to the biomedical model, and I will illustrate how these medical practices produce particular types of patients. Secondly, I will discuss the ranking and sorting of various accounts: those produced largely by diagnostic instruments with those accounts produced by patients. I will then pay particular attention to the indefinite, uncertain nature of diagnosis and argue that, based on what we have seen here, a great deal of medicine is conducted in this way: the body and body parts often escape being endowed with definite, certain form. Thirdly, I will argue that we have been witnessing the operations that constitute power. Using Foucault's rendition, I will illustrate that we have seen instances of productive power and restrictive power, and we have also seen instances where domination may occur, where the patient's account is being discarded in favour of the accounts produced by other actors. I will conclude by arguing that sociologists are well placed to challenge domination by highlighting and multiplying uncertainties. This provides a margin for alternative accounts, such as the patient's, to influence the ordering of things.

In each of the three sections we have seen how entities become intelligible. As associations formed between entities, a series of capacities for interaction were realised which generated an account. The interaction between the GP and the patient enacted a chest pain that occurred in a particular part of the body, was associated with a family history of heart disease and a history of smoking, and as not being associated with sharp, spreading pains or exertion. In the treadmill stress test, the technician and cardiologist carefully assembled the ECG device and Simons' body so that the electrical impulses of the heart would, via the movement of electrons, induce the movement of a series of inked needles on graph paper. The resulting inscription indicated that the heart was healthy and free of blockages. In the post-treadmill debrief, Simon's chest pain was enacted as an indefinite, potentially risky condition as the cardiologist employed two tactics aimed at explaining away possible contradictions between the two elements. In the process, a world based on cardiac health awareness was constructed, within which Simon was enacted as a self-responsible, vigilant individual. In each case, we have avoided prematurely assigning causation to particular entities, and we have let the actors decide which sort of elements are to be used in accounts. Consequently, we have seen how it is that medical practices produce intelligible entities, and how such entities become a source for further action; how it is that patients, GPs, specialists, technicians and medical 
instruments coordinate to build and order a world, or multiple worlds, comprised of often tangible and utilisable, but sometimes indefinite and vague, things. To put it concisely, we have witnessed the ordering of things in medical interactions.

What can we say about the various ordering practices themselves? Firstly, from following Simon's experiences in the medical system, it is unreasonable to criticize medicine for failing to take into account social and psychological elements when dealing with patients. According to the biomedical model, supposedly the dominant paradigm in modern western medicine, the body is treated as being separate to the mind, and as something which can be repaired in much the same way as a machine. Doctors, like engineers, seek to understand and treat disease according to the body's broken components, ignoring any potential social causes or explanations (Nettleton and Gustafsson 2002: 2). This biomedical model does not seem to dictate the events of Simon's GP consultation. There is certainly a focus on internal, somatic elements ("unhappy heart cells", "tropinin T", "chest wall"), but these are not at the exclusion of social and psychological elements ("broken sleep", "angsting" over the death of a close relative, "self-worth", and so on). Indeed, as we saw, the GP states that the cause is probably "existential sort of stuff”, and suggests counselling would be helpful. Similarly, in the post-treadmill debrief, Simon is entwined in talk of anxiety, eating habits, exercise and lifestyle. Social elements and explanations appear to sit side-by-side with somatic elements: the GP in particular seems to move without discord from talk about cells and organs to family histories and existential crises.

Social and psychological elements are absent from the enactment of the heart produced in the treadmill test, however. The assemblage or inscription device was arranged so that only very particular somatic elements of the body would be brought into the interaction, and, as a consequence, the heart was made intelligible in terms of its ability to adequately conduct and respond to the electrical impulses controlling heart rate. Because of the controlled nature of the procedure and the fixed composition of the instruments, there was no allowance for Simon's anxieties or opinions to influence the inscription. While his body was carefully aligned and exercised, Simon, as a potentially expressive, emotional and accounting individual was, essentially, absent. Here we are very close to a split between the mind and the physical body that is said to be symptomatic of the biomedical model. The tissues and spaces of the body were treated as if they alone could speak for the heart; not the thinking, feeling, expressive Simon. It seems, then, 
that from our examples of medicine in action, we have one instance where social and psychological elements were vital in producing intelligibility, and one instance where these sorts of elements were completely ignored. From this, we could state that it is unfair to accuse all medical practices of being dictated by the biomedical model paradigm, yet there are nonetheless practices which do conform to some of its central tenets.

In light of Mol's exposition of hospital practices, this insight into the variability of medicine in action hardly seems radical. But this variability does raise some interesting points concerning the role of medicine in enacting, or reproducing, particular types of patients. In our first location, Simon, through his responses to the GP's questions and his articulation of his anxieties, was actively involved in bringing elements into the account of chest pain. Although the GP directed the line of questioning, chest pain would not have been enacted as it was, without Simon. In the process of producing an enactment, he became a spokes-agent for his bodily-sensations; he himself was enacted, via this consultation, as a feeling, expressive, accounting individual. This contrasts with his role in the treadmill stress test. In an effort to peer into the body, to make the heart visible, Simon, who was a principal actor in producing chest pain, was effectively muted. As a patient, he was little more than a compliant body. Instead, it was the cardiologist, via the inscription device, who was the spokes-agent for the spaces within Simon's body. Here we are close to the body-as-object that Foucault refers to: the body as a tangible, fleshy assortment of tissues, within which can be found the truth of life and the processes of disease and death (Foucault 2003: 9). By having instrumentation and the cardiologist as spokes-agents, we can see how Simon, or any patient in this situation, may feel alienated from their own body. In Haraway's terms, a "God's eye" view of the body has been created via a process that does not involve a contribution from the patient himself (1991b). He is temporarily enacted as a series of interacting biological processes (aerobic metabolism, electrical impulses, a pumping heart); a physical, functional body that exists independent of a thinking, feeling, expressive person.

Yet, less than an hour after this, Simon is treated as a self-managing, selfresponsible individual by the cardiologist. Simon, as we saw, is encouraged to monitor his bodily sensations and manage his day-to-day activities in accordance with a healthy lifestyle. He is enacted as an individual who is both capable of scrutinizing his body and of making choices that will improve his health and reduce the risk of cardiac troubles: he is being endowed with the control of his own body. This is not necessarily on his terms, 
however. Simon is a vigilant, self-responsible individual, but this is within a world that has largely been constructed for him. The particular phenomena in his environment that he should be taking note of, and the strategies he should be employing, have been framed by the cardiologist. Smoking, HDL, LDL, fish, aspirin: these are some of the elements which should now become the basis for a series of actions. What it means for him to be an individual agent, then, is the consequence of the ordering practices in which he has been enacted. His capacity to act is inextricably linked with how he was enacted. A healthy cardiac lifestyle is a lifestyle based around managing and regulating oneself with an awareness of the heart as a fleshy, essential and sensitive component within the body. This resonates with Rose's comments on the relationship between biomedicine and the individual, where the knowledge produced in biomedical practices becomes a basis for particular subjectivities. The individual becomes aware of a body that is material, functional, and susceptible, and something which can be maintained via careful and active management (Rose 2007: 25-26). The types of representations and images produced by the inscription device in the treadmill test prompt an awareness of the body's corporeality, and can become the basis for self-managed, health-orientated lifestyles, in accordance with the recommendations of various experts and specialists.

Simon is therefore something of a multiple entity. In location one, he is a principal actor: an accounting, expressive agent. In location two, he is little more than a material body of functioning organs. And, in location three, he becomes a vigilant, selfresponsible individual. So, at the end of this experience in the healthcare system, what assertions could we make about Simon? What form, or translation, holds? Does he have a lingering sense of alienation from his body as a result of the treadmill test, or was this remedied by the agency he was subsequently endowed with in the debrief? Or, does he feel restricted by this knowledge of his heart and the lifestyle it entails? He may wake up the next morning having forgotten the whole experience altogether. Such questions cannot be answered here, and it is a limitation of this project that we were unable to acquire Simon's reflections on the medical practices some time later. But, nonetheless, we have glimpsed how it is that medical practices can construct patients, bodies, and individuals. The search for disease and the assembling and reassembling of elements that that entails enacts not only pains, organs, and illness, but also actors, people and worlds that extend outside the physical bounds of the consultation room and specialist clinic. Perhaps we could, using Mol's phrase, call him a patchwork singularity. The three 
assemblages enact a different patient, yet these enactments hold together as being Simon; an individual as stipulated by his accompanying medical notes, and an individual who experiences a persistent physicality. He is part self-made, part machine-made and partspecialist-made, and he is an accounting, expressive agent, a physical, functional, fleshy body, and a self-managing, self-responsible individual.

The second point we can make about the ordering practices we have witnessed is that clinical or laboratory findings will not necessarily be trusted more than the claims of the patient. If contradictions occur between the patient's account of pain and a laboratory test, it may well be that the latter is discredited. In our case, neither the GP nor the specialist appeared to doubt Simon's account of his pain. As the cardiologist employs his second tactic aimed at maintaining the cause-symptom belief, however, the results of the treadmill test are treated with considerable scepticism, and the ability of this inscription device to render the true nature of the inner spaces of the body is doubted in favour of Simon's account of his pain. Here, then, the technological-based rendering of the heart does not acquire the status of an objective, truthful reflection of reality. This finding is in contrast to the many highlighted instances in medicine where laboratory and technologybased renderings have been prioritised over the patient's subjective feelings. This has been illustrated by Rhodes et al. in regards to chronic back pain. Contradictions between the technology-based visualisations of the fleshy components of the patient's back and the patient's bodily sensations of pain are often ameliorated by framing the latter as simply being "psychological" or psychosomatic (Rhodes et al. 2002: 46). Specialists who are unable to find any visual evidence of back problems thus assume that the patients are unable to provide truthful accounts of their own back. The visible renderings produced by laboratory and clinical procedures, on the other hand, are treated as being faithful representations of reality (Rhodes et al. 2002: 38). It is easy to see that this causes considerable stress for the patients involved. Not only must they continue to endure intense pain, they also acquire a sense of being alienated from a body that, they are told, is healthy (Rhodes et al. 2002: 46).

Again, then, we are led to variability. There appears to be no universal rule dictating how conflicting accounts are juggled to achieve coherence. There may be, of course, some regularity according to the type of medical problem that is being addressed. As the cardiologist stated, the treadmill test is a "basic screening test" and "there is a chance it is wrong". The cardiologist, then, knows the test to be problematic. And 
alternatively, he knows the chest pain may have another cause: anxiety, or the stomach. Because of this knowledge, the cardiologist has no need to doubt the presence of Simon's chest pain in the form it has been enacted, and this knowledge is probably widespread among cardiologists. Cardiology, therefore, may be an area of medical practice where the patient's account of chest pain it seldom discredited. There may be, to put it another way, a general acceptance within cardiology that producing a reliable representation of the heart is difficult. Other areas of medicine, particularly those concerned with chronic back pain, may place far more importance on the representations and accounts produced by technology-based procedures and tests, and if contradictions occur, it is the accounts produced by patients that are dismissed or ignored.

Determining whether certain areas of medicine accord more weight to the reliability of particular types of accounts would require additional empirical research. No doubt, in some areas of practice, various institutional regimes would be uncovered which stipulate that particular laboratory procedures or clinical tests must be undertaken before a course of action can be decided upon, regardless of the patient's account. Such procedures constitute what Callon refers to as translation regimes (1991: 147). These essentially channel actors into various assembling practices, drastically reducing the potential enactments that could occur, and therefore only permitting certain courses of action. Access to certain specialist treatments or drug therapies may be granted only when a particular laboratory result is achieved. Uncovering such regimes would allow us to pinpoint locations where patients are accorded very little agency and risk being dominated by practices outside of their control, as the ability to adequately represent reality is transferred to specialised and physically isolated procedures operated by trained technicians.

In our case, there was no such regime and Simon's ability to produce an account of reality was not doubted. It is important to note, however, who it is that has the ability to decide which account or enactment can be trusted. In the post-treadmill test debrief, we saw that it was the cardiologist who was the principal actor in creating a symptomcause coherence, and the cardiologist who had the ability to determine which enactments could or could not be trusted. Armed with a knowledge of both the limits of the treadmill test, and other potential causes of chest pain, the cardiologist was responsible for according weight to particular enactments. Simon played no role in deciding which account or enactment could be trusted and which was less reliable. Similarly, and not surprisingly, the examples of chronic back pain illustrated by Rhodes et al., it was the 
various medical specialists who were able to declare the technology-based visualisations to be more trustworthy reflections of reality (2002: 36-38). Such cases demonstrate a degree of rigidity in medical practices. Certain individuals are invested with the capacity to rank and sort various enactments, discarding and ignoring some, while reifying others. We could easily trace how this capacity comes about: some individuals are permitted to conduct medical procedures and grant access to medical resources by regulatory associations and legislature. A high level of specialised training would be required, and such individuals would have to demonstrate a command of medical knowledge and practices that would then become the basis for ranking and sorting various enactments. In this sense, the cardiologist or any medical specialist is not so much a discrete, individual agent, but rather a conduit for action; a means by which the worldview and beliefs of various medical associations and institutions come to act on the local, immediate assembling of entities. Provided, of course, that the specialist does act in accordance with their training, and this cannot always be guaranteed.

In our case, whether we see the cardiologist as an individual agent or a network of various institutional training regimes depends on how far back we trace the lines of action, but regardless of when we decide to stop tracing associations, the cardiologist occupies an important locus. It is the cardiologist who coordinates the ranking and sorting of the enactments that have taken place, and thus it is the cardiologist that provides Simon with the final translation of his chest pain and heart. And, in an attempt to maintain symptom-cause coherence, two tactics were employed by the cardiologist: postulating another cause for the pain, and suggesting that the treadmill test generated an inadequate picture of the heart. As a consequence, only a tentative diagnosis was made. Simon was told that his heart was probably healthy, but because this could not be guaranteed, he would have to carefully monitor his bodily sensations. His heart is consequently enacted as something indefinite; something that escapes being endowed with a final, conclusive, bounded form. While it is most likely linked to anxiety, it retains a tentative association with arterial narrowings and blockages, and for this reason, it becomes intelligible in terms of risk and as a source for self-surveillance and selfmanagement.

To summarise, after having a GP consultation, enduring a treadmill stress test at a specialist centre, and then consulting with a highly trained cardiologist, the health of Simon's heart and the cause of his chest pain is still not known for certain. After mobilising a great deal of resources and specialist assistance, and the financial 
expenditure this entails, the state of Simon's heart cannot be guaranteed. It would be misleading to claim that nothing has been achieved, however. After all, as we have seen, both the GP and the cardiologist postulated anxiety as the likely cause, and the treadmill test, although not infallible, did not detect any heart troubles. The result of these medical practices is, rather than a firm diagnosis, a greater degree of assurance. There is, for the cardiologist and possibly Simon, more proof that that heart is healthy: there is no certainty, just a movement towards one possible explanation.

I suggest that a great deal of medicine operates like this. Rather than dealing with definite, well-bounded objects and the certainties that these would entail, it may be that medical professionals are dealing more with entities that escape a final, conclusive enactment. If this is so (and again, more empirical research is needed to determine this), then the work of medical professionals is not simply a process of uncovering supposed truths within and about the body; it is not a matter of an unprejudiced medical gaze revealing the true forms of body and disease. Rather, it is a matter of determining probabilities and managing risk. Uncertainty is always present: a likely cause for an illness may be foregrounded, but other potential causes are seldom eliminated. Accounts are produced, entities are enacted, and decisions are made, but medical practices do not necessarily generate a clear and definitive order of things.

It is worth asking, as a brief thought experiment, what would have provided the cardiologist and Simon with a more definitive diagnosis. There are, as the cardiologist stated, other tests that can be done to determine if the heart is the cause of Simon's pain. One such test is the coronary angiogram. X-ray images of the arteries of the heart are taken, so that any blockages or narrowings are rendered visible. To do this, however, a radio-opaque dye must be released into the patient, creating an X-ray image of shadows representing the normally transparent heart arteries. A specialist inserts a catheter into a patient and gently guides it, through the arterial system, to the opening of the coronary artery. The dye is then released directly into the heart, and the X-ray images are taken (Julian et. al. 1998). The procedure is considered to be more accurate than the treadmill stress test, and can potentially determine the exact location of any narrowings within the heart. But unlike the treadmill stress test, it is invasive. Although uncommon, the radioopaque dye can cause kidney damage or an allergic reaction. It is also much more expensive: surgical instruments and staff need to be employed, and the necessary agents are not cheap. 
In cardiac cases such as Simon, there is something of a trade-off between certainty and cost: by utilising more tests, a more accurate diagnosis may be possible, but this comes at significant cost and increased risk. The treadmill stress test is less accurate, but as the GP stated, it is "a cheap and easy test to do". It is non-invasive, extremely lowrisk, and comparatively inexpensive, and for this reason, it is the "basic screening test". Here, then, is another set of concerns for medical professionals. There may be a range of possible tests that can be utilised to determine the cause of an illness, but many require expensive, highly specialised equipment, the skills and time of a trained technician, and in some cases, opening-up the body of the patient. For these reasons, it is simply not feasible for a GP or specialist to enrol as many tests as possible in order to achieve the most accurate diagnosis. Choices have to be made, and a degree of certainty may have to be sacrificed. In the interests of both the patient's well-being and financial restrictions, some diagnostic procedures will have to be chosen over others. In our case, the cardiologist appears to be comfortable with the degree of accuracy achieved by the treadmill test. Despite the persistent uncertainty, he makes no recommendation for further testing, and instead instructs the patient to monitor his symptoms. Thus, while other tests may bring about the enactment of a more definite, well-bounded heart, such certainty is not always necessary, or not always possible.

Here we have witnessed what Foucault would refer to as relations that constitute power (1998: 92-93). In each of the three interactions, we have seen how it is that relations between various elements are brought about and how these relations produce intelligible entities. We have seen how certain actors initiate the assembling of elements, and we have seen how other actors are endowed with form by these practices. The medical practices we have been following have been both productive and repressive. They are productive in that they produce the entities that become the basis for further action. They provide an intelligibility that allows us to talk about, manage, and rationalise things: Simon's chest pain, the health of his heart, Simon as a self-responsible individual. These medical practices are restrictive in that by bringing certain elements into an account, many other potential elements are excluded or ignored. In the process of making an object intelligible, a myriad of other potential forms are inhibited. We have seen that in the treadmill stress test, there was no allowance for Simon to influence the construction 
of the reality of his own heart. Here, then, we have examples of power as both productive and restrictive.

We have also seen how this power, as Foucault suggests (1998: 94), is diffuse. Rather than being possessed by some sort of dominating elite, it is exercised from innumerable points: in each of the interactions we studied, the actors initiating the assembly of entities varied. Spokes-agents and actors changed as entities assembled and reassembled. There is considerable fluctuation in medical practices: in some cases the patient is a principal actor in producing accounts, and in other cases they are excluded. We have also glimpsed some instances of durability: the treadmill stress test involved highly trained staff and fixed instrumentation and Simon was therefore placed in a highly-ordered, controlled environment. To use Tarde's concept (1893), the way in which monadic complexity is being translated into an intelligible account is set by the durable nature of the technology and training of the medical professionals. I have also suggested that durability is provided via the institutionalised stipulation that the cardiologist, as a specialist, is permitted to coordinate alternative accounts. So although a diagnostic testbased account, such as that produced by the treadmill stress test, may not necessarily be prioritised over the account produced by a patient, it is only the medical specialist who can rank and sort these accounts with any legitimacy.

We have also exposed the operations of biopower (Foucault 1998: 143). We have seen how medical practices in the consultation room can come to shape the everyday behaviour of individuals by encouraging them to self-monitor and self-manage themselves according to conceptions of "healthy living". In our examples, the three interactions provided a somatic awareness; and understanding of chest pain and the heart that could then become the basis for style of life aimed at maximising health. If Simon follows the advice he has been given, then he will be governing himself according to the cardiologist's understanding of healthy cardiac living. Medical knowledge therefore lends itself to self-governance. A particular subjectivity is being encouraged where individuals understand themselves in terms of material, somatic elements, while being persuaded to actively manage their own health and well-being via the mediation of a medical authority.

So now that we have exposed the relations that constitute power, described how accounts are produced and sorted, and noted how entities become intelligible, where do we go from here? Is there any utility to the Actor-network theory we have adopted? To 
put the question succinctly: is there any point to this, outside of providing our own descriptive account of medicine? Can we contribute to a political project aimed at eliminating the conditions of domination, which has been the impetus of sociology since its inception? My answer is yes, we can. By gaining a knowledge of how others go about constructing reality, discerning facts from non-facts, and how some accounts become more "objective" than others, we will be well-placed to counteract those situations where domination or repression can occur. Such situations may occur when one account is said to represent reality and all other accounts are dismissed, or when a patient is repeatedly muted in the production of accounts of their own body. We saw how instruments can produce accounts of the body while not allowing individuals themselves to contribute. If such an account was then held up as being factual and objective, and at the expense of potential conflicting accounts produced by the patient, then we can see how domination may occur, particularly if the resulting translation prevents access to particular courses of action. In this sense, then, domination is a matter of being cut-off from contributing to the construction of reality; being prevented from defining your own body with any "factual" weight, as discussed with Rhodes et al.'s (2002) examples of patients with back pain.

A useful strategy, then, is to highlight and multiply uncertainties. We have seen in Simon's case that uncertainty was part of medical practices and did not seem to be problematic. The cardiologist appeared to exercise the belief that generating an exact picture of cardiac health is difficult, and thus he treated the treadmill stress test as being fallible. Indeed, as Lloyd points out, if you follow the experts at work, you will find that medicine, like science, is not full of absolute answers. Rather, it is characterised by debate, ambiguity, controversies and uncertainties (Lloyd 2000: 158). Even when employing instrumentation and undergoing diagnostic tests, objects, as we have seen with Simon's heart, can escape being endowed with a definitive, absolute form. This provides a margin for other explanations, other accounts, and thus other actors to appear. The cardiologist's doubt about the treadmill stress test, along with the enactment linking his chest pain to anxiety, meant that Simon's account of his pain did not have to be discarded or ignored: the multiplicity of accounts and the resulting uncertainty enabled Simon to define parts of his own body with some legitimacy. Simon, then, has not been excluded from constructing the reality that becomes the basis for further actions concerning his body. If indeed uncertainty and ambiguity is common to medical practice, and if such uncertainty provides some room for alternative accounts, 
particularly those of patients, then the sociologist is well-placed to challenge those situations where certainty is being claimed, particularly if a patient's account has been elided. This would require uncovering those practices being employed to prevent the possibility of any controversy; in particular, noting which actors are involved in making a translation durable enough so that any other accounts are discarded.

In effect, the sociologist is seeking to challenge domination by preventing the definitive culling of elements from accounts and thus encouraging the persistence of numerous associations. Obviously, there are times when a definitive diagnosis has occurred in medicine and it is not problematic for those concerned. The diagnosis of a bacterial infection, for instance, is a likely example where both the medical professional and the patient are pleased with the resulting certainty. But, in situations where a definitive translation is causing considerable distress (and here I have Rhodes et al's chronic back pain sufferers in mind), it may be therapeutic to challenge the reality that is being claimed, open-up the uncertainties, and therefore provide a margin for the patient's accounts. The task, then, is to insure the patient and their body is sufficiently interconnected to allow room for multiple enactments to occur. In this way, the patient retains the ability to define and delimit their body and themselves according to a wider range of elements, not just those that inhabit the diagnostics lab or the specialist clinic. In a sense we are promoting the same sort of interconnectivity as Haraway in her "Cyborg Manifesto" (1991). Freedom can be found in the confusion that results in the lack of definitiveness. Uncertainty, vagueness, and the permeability of boundaries results in a profusion of spaces for making identities; a resource for the self-construction of one's body and one's body-politic (Haraway 1991: 151). There is, then, a freedom to be garnered from uncertainty; a freedom from being dominated by a single viewpoint, a viewpoint that is the product of a single, definitive construction of reality, or a misguided belief in a single, well-bounded order of things.

I have had two objectives in undertaking this project. The first has been to argue in favour of an Actor-Network theory-based approach to studying medical practices. There is, I have argued, much to be gained from forfeiting the assumptions that characterise more traditional sociological approaches. By jettisoning any a priori divisions between social and non-social elements, discarding the macro/micro distinction, and accepting that any element may become an actor, we can determine how it is that medical practices produce intelligibility and thus construct patients, bodies, and subjectivities. 
Consequently, I have attempted to demonstrate that rather their being an absolute order of things, there is a constant assembling and reassembling; a constant ordering of things. My second objective, then, has been to argue that with a knowledge of how medical practices order the world, sociologists are well-situated to counteract situations where domination may occur. By exposing the relations that constitute power, and armed with a knowledge that uncertainty and ambiguity is often common and non-problematic in medicine, we can promote multiplicity and thus provide a margin for alternative enactments and accounts to have an influence in the ordering of the world. Like all projects, the need for more empirical research has been highlighted. We have followed one patient through primary and secondary care. For my arguments to carry more weight, it would be necessary to follow more patients: men and women, in both primary and secondary care, and in different specialist areas. 


\section{Bibliography}

Akrich, M. (1989). “La construction d'un système socio-technique. Esquisse pour une anthropologie des techniques' Anthropologie et Societés, 13(2), 31-54.

AstraZeneca, (2005). Astrazeneca And Atherogenics Announce Late Stage Licensing And Commercialisation Agreement For Novel Atherosclerosis Drug AGI-1067. Retrieved July 1, 2009, from http://feed.ne.cision.com/wpyfs/00/00/00/00/00/06/B7/48/wkr0019.pdf

Bendelow, G. A. and Williams, S. J. (1995). "Transcending the Dualisms: Towards a Sociology of Pain". Sociology of Health and Illness, 17(2), 139-165.

Callon, M. (1986). "Some Elements of a Sociology of Translation: Domestication of the Scallops and the Fishermen of St Brieuc Bay". In J. Law (Ed.), Power Action and Belief: A New Sociology of Knowledge? (pp. 196-223). London: Routledge \& Kegan Paul.

Callon, M. (1991). “Techno-economic Networks and Irreversibility” In J. Law (Ed.), A Sociology of Monsters: Essays on power, Technology and Domination (pp. 132-165). London: Routledge.

Callon, M. (1999). “Actor-Network Theory - The Market Test”, In J. Law and Hassard, J. (Eds.), Actor Network. Theory and After. (pp 181-195). Oxford: Blackwell Publishing.

Callon, M. and Rabeharisoa, V. (2004). "Gino's Lesson on Humanity: Genetics, Mutual Entanglements and the Sociologist's Role". Economy and Society, 33(1), 1-27.

Cheong, R. (2004). Pathophysiology of Atherosclerosis. Retrieved July 1, 2009, from http://www.raymondcheong.com/Year2/section4/DB13 - Pathophysiology of Atherosclerosis.doc

Conrad, P. (1979). "Types of Medical Control” Sociology of Health and Illness, 1(1), 1-11.

Corea, G. (1987). Man Made Women. Indiana University Press.

DeLanda, M. (2002). Intensive Science and Virtual Philosophy. London: Continuum.

DeLanda, M. (2006). A New Philosophy of Society: Assemblage Theory and Social Complexity. London: Continuum.

Durkheim, E. (1912/1995). The Elementary Forms of Religious Life. New York: The Free Press.

Durkheim, E. (1982). Lukes, S. (Ed.), The Rules of Sociological Method and Selected Texts on Sociology and its Method. London: McMillan.

Durkheim, E. (1984). The Division of Labour in Society. Basingstoke: Macmillan.

Engel, G. L. (1981).“The Need for a New Medical Model: a Challenge to Biomedicine” In (A. L. Kaplan, H. T. Englehart and J. J. McCartney (Eds.), Concepts of Health and Disease: Interdisciplinary Perspectives. London: Addison Wesley.

Fairfield, P. (1994). "Habermas, Lyotard and Political Discourse". Reason Papers: A Journal of Interdisciplinary Normative Studies, 19, 58-80.

Foucault, M. (1977). Discipline and Punish: The Birth of the Prison. New York: Pantheon Books. 
Foucault, M. (1996). “The Ethics of the concern of the Self” In S. Lotringer (Ed.), Foucault Live: Michel Foucault Collected Interviews, 1961-1984. New York: Semiotext(e).

Foucault, M. (1998). The History of Sexuality Volume 1: The Will to Knowledge. Middlesex: Penguin Publishers.

Foucault, M. (2003). The Birth of the Clinic: An Archaeology of Medical Perception. London: Routledge Classics.

Hacking, I. (1992). "The Self-Vindication of the Laboratory Sciences". In A. Pickering (Ed.), Science as Practice and Culture (pp 29-64). Chicago: University of Chicago Press.

Haraway, D. (1991a). “A Cyborg Manifesto: Science, Technology, and Socialist-Feminism in the Late Twentieth Century" In Simians, Cyborgs and Women: The Reinvention of Nature (p. 182). New York: Routledge.

Haraway, D. (1991b). "Situated Knolwedges: The Science Question in Feminism and the Privilege of Partial Perspective" In Simians, Cyborgs and Women: The Reinvention of Nature (pp. 183-202). New York: Routledge.

Julian, D. G., Cowan, J. C., McLenachan, J. M. (1998). Cardiology. New York: Saunders Co.

Kuhn, T. (1977). "Objectivity, Value Judgement, and Theory Choice" In The Essential Tension: Selected Studies in Scientific Tradition and Change (pp. 320-339). Chicago: University of Chicago Press.

Kuhn, T. (1996). The Structure of Scientific Revolutions. Chicago: University of Chicago Press.

de Laet, M. and Mol, A. (2000). "The Zimbabwe Bush Pump: Mechanics of a Fluid Technology" Social Studies of Science, 30(2), 225-263.

Latour, B. (1986). "The Powers of Association". In J. Law. (Ed.), Power, Action and Belief: A New Sociology of Knowledge? (pp. 264-280). London: Routledge \& Kegan Paul.

Latour, B. (1987). Science in Action: How To Follow Scientists and Engineers Through Society. Cambridge MA: Harvard.

Latour, B. (1992). "Where are the missing masses? The sociology of a few mundane artefacts" In Bijker, W. E. and Law, J. (Eds.), Shaping Technology/Building Society: Studies in Sociotechnical Change. Mass.: MIT Press.

Latour, B. (2001). "Gabriel Tarde and the End of the Social" downloaded from http://www.bruno-latour.fr/articles/article/082.html

Latour, B. (2004). "How to Talk About the Body? The Normative Dimension of Science Studies" Body \& Society 10(2-3), 205-229.

Latour, B. (2005). Reassembling the Social: An Introduction to Actor-Network-Theory. New York: Oxford.

Latour, B. and Woolgar, S. (1986). Laboratory Life: The Construction of Scientific Facts. Second edition. Princeton: Princeton University Press.

Law, J. (1986). "On the Methods of Long-Distance Control: Vessels, Navigation and the Portuguese Route to India" In J. Law. (Ed.), Power, Action and Belief: A New Sociology of Knowledge? (pp. 234-263). London: Routledge \& Kegan Paul.

Law, J. (1991). "Power, Discretion and Strategy". In J. Law (Ed.), A Sociology of Monsters: Essays on power, Technology and Domination. London: Routledge 
Law, J. (2004). After Method: Mess in Social Science Research. London: Routledge.

Levine, D. (1995). Visions of the Sociological Tradition. Chicago: University of Chicago Press.

Lloyd, M. (2000). "Analysis on the Move: Deconstructing Troublesome Health Questions and Troubling Epidemiology." Qualitative Health Research, 13(2):149-163

McGrail, R. (2005). "Risky Maps for Contested Territories: Reassembling the Social: An Introduction to Actor-Network Theory." New Zealand Sociology, 20(2), 121-131.

May. T. (2006). The Pbilosophy of Foucault. Montreal: McGill-Queens University Press.

Ministry of Health, Manatû Hauora (2006). Mortality and Demographic Data 2002 and 2003. Retrieved July 1, 2009, from http://www.nzhis.govt.nz/moh.nsf/pagesns/71?Open

Ministry of Health, Manatû Hauora (2009). Healtby Eating, Healtby Action. Retrieved July 1, 2009, from http://www.moh.govt.nz/healthyeatinghealthyaction

Mol, A. (1999). "Ontological Politics. A Word and Some Questions", In J. Law and J. Hassard (Eds.), Actor Network Theory and After (pp. 74-89). Oxford: Blackwell Publishing.

Mol, A. (2002). The Body Multiple. London: Duke University Press.

Nettleton, S. (1992). Power, Pain and Dentistry. Buckingham: Open University Press.

Nettleton, S. (1995). The Sociology of Health \& Illness. Cambridge: Polity Press

Nettleton, S. and Gustafsson, U. (2002). "Introduction" In S. Nettleton, and U. Gustafsson, (Eds.). The Sociology of Health and Illness Reader (pp. 1-10). Cambridge: Polity Press.

Nippert, M. (2008). "Staying Alive: Writer David Slack Celebrated His 21st for the Second Time”. New Zealand Listener, 214(3553), 20

Pasveer, B. (1989). "Knowledge of Shadows: The Introduction of X-ray Images in Medicine" Sociology of Health \& Illness 11(4), 360-381

Pottage. A. (1998). "The Inscription of Life in Laws: Genes, Patents and Biopolitics". In R Brownsword, W.R. Cornish and M. Llewelyn (Eds.), Law and Human Genetics: Regulating a Revolution (pp. 148-173). Oxford: Hart.

Prout, A. (1996). "Actor-Network Theory, Technology and Medical Sociology: an Illustrative Analysis of the Metered Dose Inhaler" Sociology of Health \& Illness, 18(2):198-219

Rabinow, P. (1991). The Foucault Reader: An Introduction to Foucault's Thought. London: Penguin Books.

Rabinow, P. (1996). “Artificiality and Enlightenment: From Sociobiology to Biosociality" In Essays on the Anthropology of Reason. (pp. 91-111). New Jersey: Princeton University Press.

Rhodes, L. A., McPhillips-Tangum, C. A., Markham, C. and Klenk, R. (2002). In S. Nettleton, and U. Gustafsson, (Eds.), The Sociology of Health and Illness Reader (pp. 35-47). Cambridge: Polity Press.

Rose, N. (2001). “The Politics of Life Itself” Theory, Culture and Society 18(6), 1-30.

Rose, N. (2007). The Politics of Life Itself: Biomedicine, Power, Subjectivity in the Twenty-First Century. New Jersey: Princeton University Press. 
Shilling, C. and Mellor, P. A. (1998). "Durkheim, Morality and Modernity: Collective Effervescence, homo duplex and the Sources of Moral Action. In The British Journal of Sociology. 49(2), 193-209.

Sober, E. (2000). Philosophy of Biology: Second Edition. Boulder: Westview.

Strathern, M. (1999). “What is Intellectual Property After?”. In Property, Substance and Effect. (pp. 179-204). London: Athlone.

Tarde, G (1893/1999). Monadologie et Sociologie. Paris: Les emecheurs de penser en rond.

Timmermans, S. and Berg, M. (2003). "The Practice of Medical Technology" Sociology of Health and Illness, 25:97-114.

Waldby, C. (2000). The Visible Human Project. London: Routledge.

Westwood, S. (2002). Power and the Social. London: Routledge. 